\title{
Natural Phenolic Compounds and Derivatives as Potential Antimalarial Agents
}

\author{
Authors \\ Lucia Mamede, Allison Ledoux, Olivia Jansen, Michel Frédérich
}

\begin{abstract}
Affiliation
Laboratory of Pharmacognosy, Center of Interdisciplinary Research on Medicines (CIRM), University of Liège, Belgium
\end{abstract}

Key words

phenolic compounds, malaria, Plasmodium, antimalarials, antiplasmodial, natural compounds

received December 16, 2019

revised March 27, 2020

accepted March 29, 2020

Bibliography

DOI https://doi.org/10.1055/a-1148-9000

published online April 23, 2020 | Planta Med 2020; 86: 585-

618 ๑ Georg Thieme Verlag KG Stuttgart · New York I

ISSN 0032-0943

Correspondence

Prof. Dr. Michel Frédérich

Université de Liège, CIRM Laboratoire de Pharmacognosie

CHU B36 Av Hopital 1, B36 4000 Liège, Belgium

Phone: + 3243664330 , Fax: + 3243664332

m.frederich@ulg.ac.be

\section{ABSTRACT}

Malaria is a parasitic disease endemic to tropical and subtropical regions responsible for hundreds of millions of clinical cases and hundreds of thousands of deaths yearly. Its agent, the Plasmodium sp., has a highly variable antigenicity, which accounts for the emergence and spread of resistance to all available treatments. In light of this rising problem, scientists have turned to naturally occurring compounds obtained from plants recurrently used in traditional medicine in endemic areas. Ethnopharmacological approaches seem to be helpful in selecting the most interesting plants for the search of new antiplasmodial and antimalarial molecules. However, this search for new antimalarials is complex and time-consuming and ultimately leads to a great number of interesting compounds with a lack of discussion of their characteristics. This review aims to examine the most promising antiplasmodial phenolic compounds (phenolic acids, flavonoids, xanthones, coumarins, lignans, among others) and derivatives isolated over the course of the last 28 y (1990-2018) and discuss their structure-activity relationships, mechanisms of action, toxicity, new perspectives they could add to the fight against malaria, and finally, the difficulties of transforming these potential compounds into new antimalarials.
ABBREVIATIONS

ACT artemisinin-based combination therapy

$\mathrm{IC}_{50} \quad$ half-inhibitory concentration

MoA mechanism(s) of action

ROS reactive oxygen species

SI selectivity index

\section{Introduction}

Malaria is a parasitic disease endemic to tropical and subtropical regions with a worldwide distribution. Despite global efforts to eradicate it, the most recent report by the World Health Organization demonstrates a halt toward this goal [1]. In fact, 405000 deaths are estimated to have taken place in 2018, of which $67 \%$ were children under the age of 5 , one of the most vulnerable groups [1]. This represents a slight improvement, in comparison to 2017, in terms of mortality; however, the incidence rate change has slowed dramatically in the last $4 y$, revealing that, globally, the burden of this disease remains an issue toward eradication. The protozoan responsible for this disease, the Plasmodium sp., is transmitted through the bite of a female Anopheles sp. mosquito. Of the 5 human infecting species, Plasmodium falciparum and $P$. vivax represent the highest burden and the majority of cases [1-4]. P. falciparum remains the most prevalent and deadly, particularly in Africa, with increasing resistance to antimalarial therapy and reports of severe malaria cases, while $P$. vivax represents an additional problem of recurrence derived from its ability to remain in the host's liver as an hypnozoite, a dormant parasitic form that can reactivate and cause the disease later on $[1,5]$.

Overall, the World Health Organization's eradication program faces several obstacles. Reports reveal that important factors-incidence and burden, for instance-show signs of slow evolution, particularly in Africa and India [1]. Other problems are responsible for this outcome, such as a difficult access to antimalarial therapies and healthcare, inadequate funding, and, in some cases, cul- 


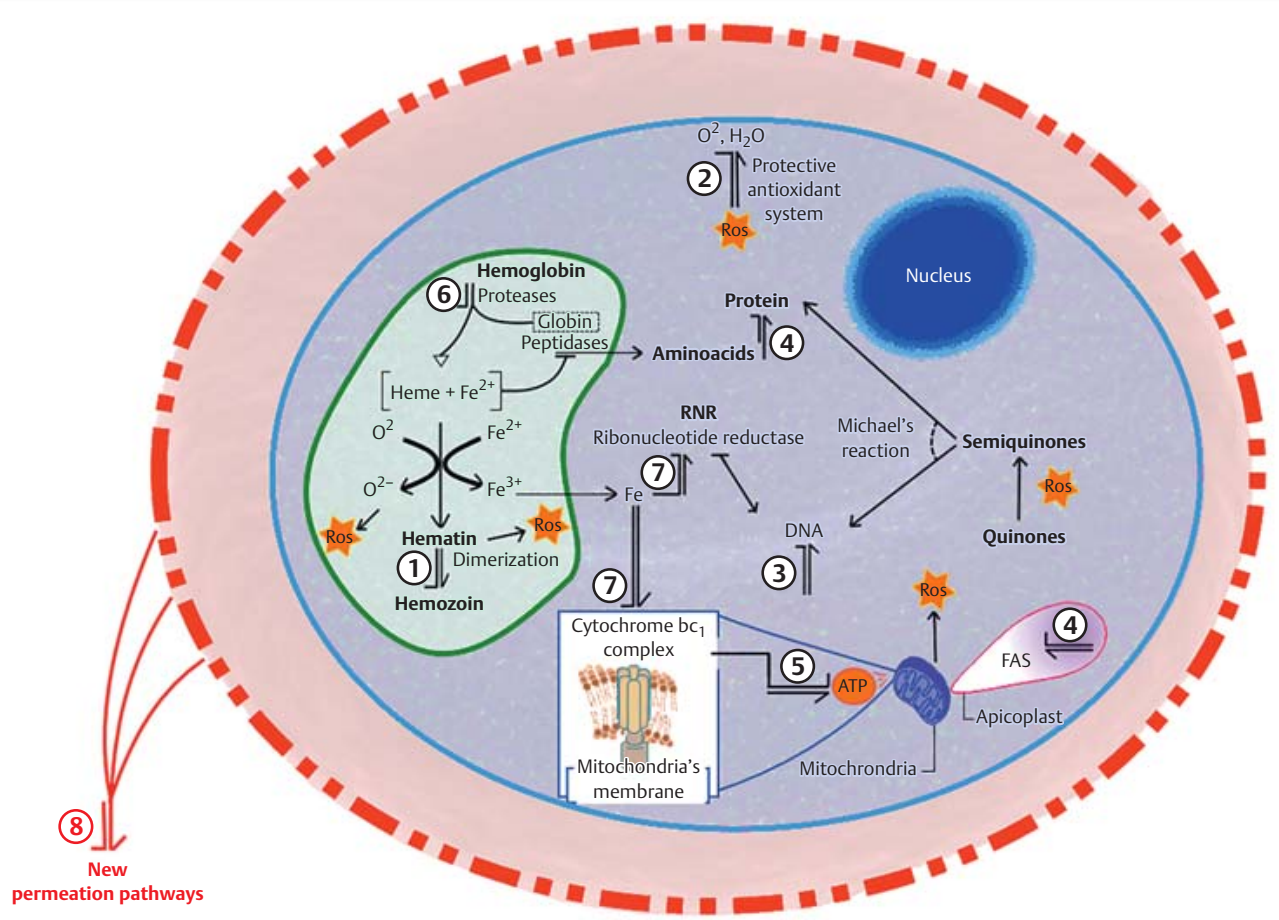

- Fig. 1 Representation of an intra-erythrocytic Plasmodium falciparum trophozoite, highlighting key parasite intracellular pathways and the site of action of phenolic compounds. 1 Inhibition of the formation of hemozoin; 2 Inhibition of the redox homeostasis; 3 Inhibition of the DNA synthesis; 4 Inhibition of the synthesis of proteins or fatty acids (FAS); 5 The inhibition of the cytochrome $b c_{1}$ complex of the mitochondria's respiratory chain; 6 Inhibition of the digestion of hemoglobin; 7 Iron chelation; 8 Inhibition of new permeation pathways. The interference with any or multiple indicated pathways leads to the parasite's death.

tural barriers in the use of modern therapies [1]. Undeniably, these complications are intrinsically connected and, ultimately, lead the population to find other solutions.

Traditional medicine is still recurrently used to treat many infectious diseases $[6,7]$. The availability, low cost, and traditional knowledge that conveys trust in its efficiency are factors that sway populations to rely deeply on plants [8]. Ethnopharmacology has allowed the combination of both traditional and modern pharmaceutical approaches in order to discover novel compounds and screen them for diverse activities [7,8]. Particularly in malaria, a great number of decoctions, teas, and other preparations from plants are traditionally used across different endemic countries $[6,7]$. Their advantage is that acute toxicity is unlikely since their use was established from centuries of experience of trial and error $[9,10]$. Additionally, this incommensurable pool of compounds has already contributed to the majority of modern antimalarials [4, 6, 7, 9-12]. Examples are quinine and artemisinin, which are largely used today $[3,9,13-16]$. These compounds paved the way for synthetic antimalarial derivatives to be designed and now represent the foundation of the antimalarial therapies, both in the form of ACTs and individually [15-17]. In the same way, other natural compounds could contribute in a similar fashion. Phenolic compounds and their derivatives are a group of phytochemical substances found in virtually every plant. Despite their wide presence and recognized value for health purposes, they are one of the least explored classes, and there is a lack of an integral review on their characteristics and effects on the malaria parasite.

This review aims to integrate and discuss the most promising antiplasmodial phenolic compounds and derivatives isolated from plants over the last 28 y (1990-2018). To gather relevant information, reviews and single publications from that time period were searched on PubMed, Science Direct, SciFinder, and similar databases using relevant keywords, such as the classes of phenolic compounds and malaria and/or Plasmodium sp. $[2,7,13,14,18-$ 27]. Compounds were selected according to their $\mathrm{IC}_{50}(\mu \mathrm{M})$ in in vitro assays with $P$. falciparum different strains: chloroquine-sensitive (3D7, D6, F32, NF54, T9-96, D10), chloroquine-resistant (Dd2, FcB1, FcB2, W2, Fcm29, RKL 303, PFB, BHZ 26/86), multidrug-resistant (K1, NHP1337), and/or multidrug-sensitive (HB3, FCR-3). The $\mathrm{IC}_{50}$ threshold was established as $2 \mu \mathrm{M}$ or less, as according to several reviews that deem it as an acceptable limit predictive of progress into drug development $[22,28]$. Attention was given to cytotoxicity tests to attain the SI, the measurement of differentiated toxicity toward the parasite, and to the plant's history as a traditionally used medicine [9]. The purpose of this review is to highlight and compare potential antimalarial hits within the phenolic phytochemical class and to discuss structure-activity, MoA, and new perspectives these compounds could add to the fight against malaria. - Fig. 1 gives an overview of important parasitic pathways that are known targets of antimalarials. Com- 
pounds were selected according to the aforementioned criteria and included in the discussion whenever they impacted research. They are organized by phytochemical classes and displayed in tables with pertinent information, for easy consultation.

\section{Lead Phenolic Antimalarial Compounds from Plants}

Phenolic compounds are frequent in plants and are distributed within numerous phytochemical classes. They are broadly defined by their molecular structure, with 1 or more aromatic rings, without a nitrogen, originated from plant's metabolism pathways of the shikimate and/or acetate. The shikimate pathway starts from the same-named acid, which in turn originates aromatic amino acids that, after deamination, create cinnamic acid and derivatives, like phenylpropanoids. The acetate pathway originates $\beta$ polyketide acids that can undergo cyclization steps to create phenolic compounds. From these routes, distinct groups of compounds can be identified, such as coumarins, flavonoids, tannins, stilbenes, lignans, quinones, xanthones, and chalcones, among others. It is frequent that a hydroxyl group is associated to the aromatic ring, either free or as a part of other chemical functions, (e.g., esters, ethers, or glycosides). When this functional structure is repeated, the compound is named a polyphenol $[29,30]$. Phenolic compounds incur oxidation reactions easily, which makes them strong radical scavengers.

\section{Phenolic Acids, Phenols, and Derivatives}

Phenols are aromatic compounds that occur very rarely in a free form in a plant, usually being present glycosylated or as polyphenols. Similarly to other phenolic derivatives, when ingested orally, glycosides might be hydrolyzed in the digestive tract, which releases the aglycone. These compounds are derivates of the benzoic acid and can be hydroxylated, as in the case of the derivatives of gallic acid and its dimer, ellagic acid [30]. Although simple, this class has prompted interest in some isolates: methyl gallate (1) and compounds with the gallate/galloyl moiety; ellagic acid (3), and curcumin (5), shown in > Fig. 2 . Methyl gallate (1) exists widely in the plant's kingdom and, more importantly, is reported in plants traditionally used against malaria [31]. With many testified activities, such as antibacterial and antiviral, (1) has been considered a substance of interest since the 1980s [32]. An in vitro test with a variation of exposure time with the multi-resistant strain Dd2 was performed to determine the stage-specific activity of (1). Contrarily to quinine, which significantly affected the parasite growth throughout the entire life cycle, compound (1) had its highest activity on the late stages of the parasite (late trophozoite and schizont) [31], thus possibly limiting its effectiveness against the disease [31]. In spite of its demonstrated synergy with quinine or additivity with artemether, its highly variable $\mathrm{IC}_{50}$ between different strains cautions for limited activity, particularly against resistant strains [31]. Although its MoA has not been elucidated, data suggests the hydroxy groups of the gallate moiety could play a pivotal role as donors in the establishment of bonds where the compound would exercise its activity. Other compounds with the gallate/galloyl moiety have been reported to have antimalarial activity, some of which will be explored in this review. Unfortunately, these compounds have broad $\mathrm{IC}_{50}$ values, and it is not clear if they are selective toward the parasite. It would seem these moieties alone are not sufficient to produce potent antimalarials, but their existence might improve this activity, which will be discussed later $[33,34]$.

Ellagic acid (3) is a common metabolite found across over 40 species of plants and vegetables like the pomegranate fruit, a well-known source [35-37]. Present freely or in complex compounds (ellagitannins), it's constituted by a hydrophilic moiety, 4 hydroxyls, and a lipophilic moiety, 2 hydrocarbon rings that render it the capability to act both as an acceptor and donor of electrons. This activity makes (3) act as a preventive and potent antioxidant, with the capability of passing the cellular membranes and entering the parasite. However, it has been reported that this same structure diminishes its oral bioavailability [30,35-37]. In the malaria context, (3) has demonstrated a high degree of activity. Its presence as the active component in several traditionally used plants against malaria has originated many studies and generated great interest $[33,35,38]$. Some assays also demonstrate ellagic acid's curative and prophylactic effects in vivo. For example, Soh et al. [37] demonstrated that in mice infected with Plasmodium vinckei petteri treated with (3) at 1,50 , and $100 \mathrm{mg} / \mathrm{kg} /$ day intraperitoneally in a 4-day suppressive test, the effective dose was inferior to $1 \mathrm{mg} / \mathrm{kg} /$ day and, above this dose, a full inhibition of parasite growth was attained. Additionally, at 50 and $100 \mathrm{mg} / \mathrm{kg} /$ day, no recrudescence was detected over the next 60 days. Likewise, at $10 \mathrm{mg} / \mathrm{kg} /$ day intraperitoneally for 4 days before inoculation, a high protective effect was demonstrated, assuring survival by day 9 post-infection. After oral administration, however, the results were in line with the known low bioavailability of this compound $[30,35,36]$. Even at the highest dose of $1 \mathrm{~g} /$ $\mathrm{kg} /$ day, no antimalarial activity was reported. Toxicity tests proved its safety in mice, with no toxicity up to $1 \mathrm{~g} / \mathrm{kg} /$ day. Besides its antiplasmodial activity in the nM range (see - Table 1), (3) demonstrated synergy with chloroquine, atovaquone, mefloquine, and artesunate in in vitro assays [37]. It's important to note that these results occur directly in the erythrocytic stage or when administered intraperitoneally and do not translate to human effectiveness. It is known that ellagic acid's activity in the erythrocytic cycle occurs on the trophozoite and early schizont forms of the parasite, the most active regarding DNA and protein synthesis $[37,39]$. When compared to ellagitannins, which have a better oral absorption and can be metabolized into free ellagic acid, the $\mathrm{IC}_{50}$ is over 10 times the needed concentration for (3) for the same in vitro activity [35]. The MoA of (3) is also a matter of discussion. One of the mechanisms might be similar to quinolines, preventing the formation of hemozoin. Its flat molecular structure endows it a dispersed electronic density that allows the formation of a $\pi-\pi$ complex [40]. Another mechanism might be the inhibition of enzymes responsible for the digestion of hemoglobin, like plasmepsins, although this occurs in concentrations too high in comparison to those presented in $\mathbf{D}$ Table $\mathbf{1}$; see $\boldsymbol{\nabla}$ Fig. $\mathbf{1}$ for context [40]. Finally, in theory, it might act through its chelating properties, with the formation of coordination bonds with the iron present in heme [40]. Ultimately, (3) demonstrates a broad range 
<smiles>COC(=O)c1cc(O)c(O)c(O)c1</smiles><smiles>O=c1oc2c(O)c(O)cc3c(=O)oc4c(O)c(O)cc1c4c23</smiles><smiles>COC(=O)c1c(C)cc(OC(=O)c2c(O)cc(O)c(C=O)c2O)c(C)c1O</smiles>

2<smiles>CCCCCCCOC(=O)c1cc(O)c(O)c(O)c1</smiles><smiles>COc1cc(/C=C/C(=O)/C=C(O)/C=C/c2ccc(O)c(OC)c2)ccc1O</smiles>

5<smiles>C=CC(C)(CCC=C(C)CCC=C(C)C)c1ccc(O)c(O)c1</smiles>

- Fig. 2 Molecular structures of phenolic acids, phenols and derivatives.

of mechanisms and a high selectivity toward the parasite, but its low oral absorption has to be circumvented, and its activity in a small part of the parasite's cycle makes it an unlikely antimalarial candidate without further optimization [37].

Curcumin (5) is a phenylpropane, a derivative of caffeic acid, isolated from the roots of Curcuma longa, a food plant reportedly used for over $5000 \mathrm{y}$ [41-44]. The interest in this compound originated from its common dietary use, lack of toxicity, and varied pharmacological activities [42]. Studies have demonstrated its immunomodulating, antiparasitic, antioxidant, anti-inflamma- tory, antiviral, antibacterial, and anticancer properties [41-45]. According to the literature, curcumin's antiplasmodial activity in vitro ranges from $5-30 \mu \mathrm{M}$, in both chloroquine-sensitive and -resistant strains, well above the active threshold recognized for natural compounds [22, 25, 43-47]. In spite of this, the aforementioned interesting features of (5) led researchers to study its MoA to reach a conclusion on what (5) could add to the fight against malaria. There are at least 5 proposed MoA for curcumin that allowed the validation of several potential targets in the parasite. First, it inhibited $\mathrm{Ca}^{2+}$-ATPase of the sarcoplasmic-endoplasmic 


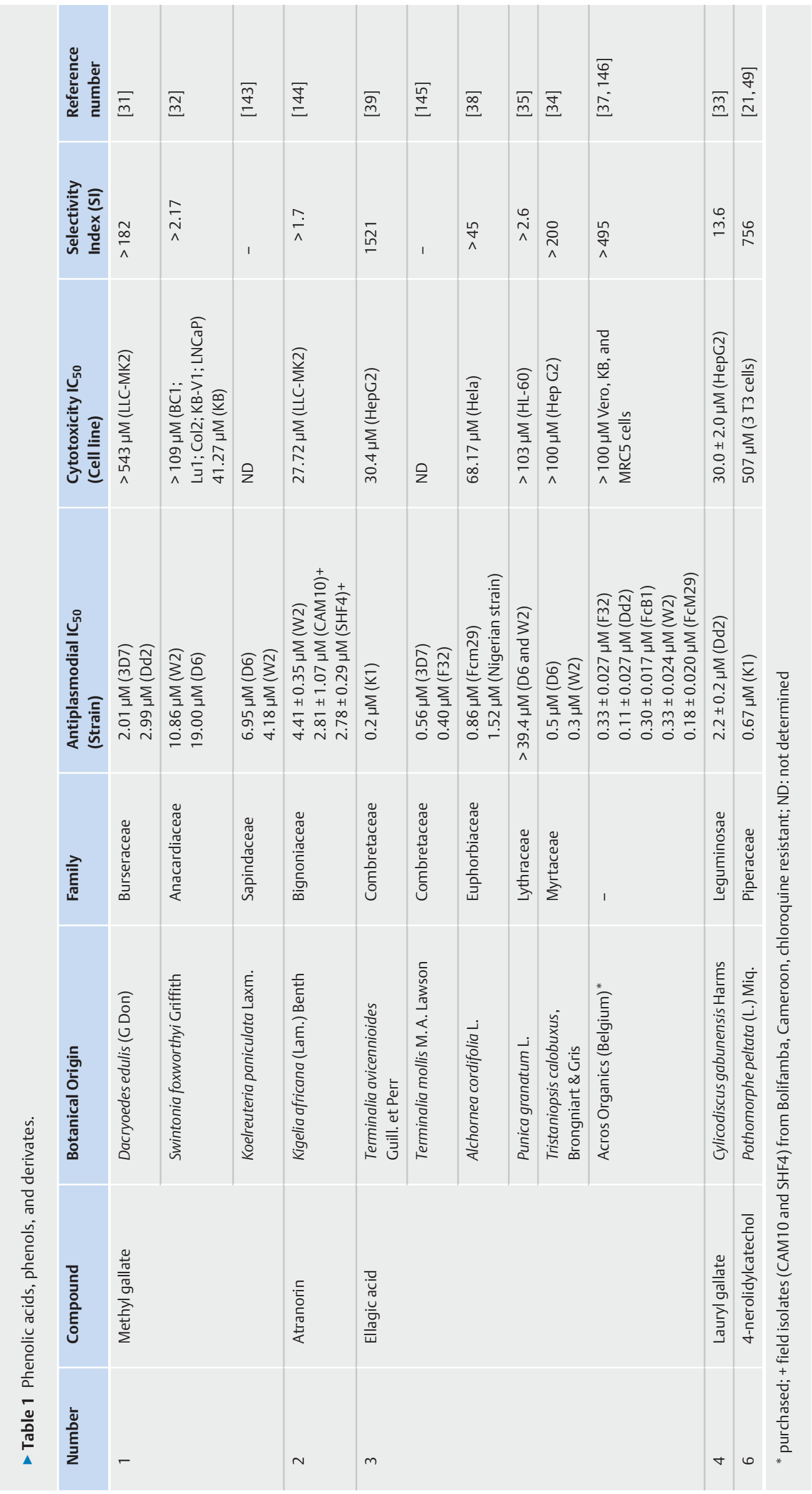




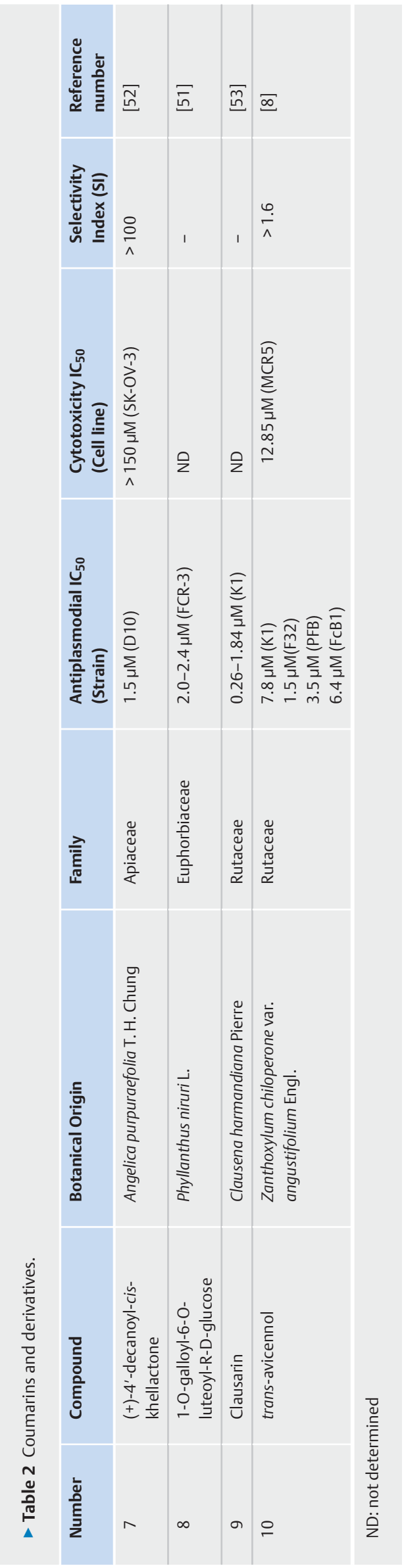

reticulum, leading to metabolism arrest $[43,44,46,47]$. Second, it enhanced cytosolic $\mathrm{Ca}^{2+}$ activity and ceramide formation, which lead to the phagocytosis of the red blood cell [47]. Third, in certain conditions, like a range of concentration of $20-100 \mu \mathrm{M}$ and the presence of transitional metal ions, (5) behaves like a pro-oxidant, possibly through its o-methoxyphenol group and methylenic hydrogen, and increases ROS production, originating damaged DNA and proteins $[43,45,47,48]$. Fourth, (5) inhibits histone acetyltransferases, which are required for chromatin arrangement and transcriptional activation [43,45-47]. Fifth, more recently it has been demonstrated that (5) disrupts the parasite's microtubule structure, interfering with processes such as merozoite formation, invasion of erythrocytes, and nuclear division, although this was only effective at the second cycle of the same culture [46]. Evidently, (5) remains an interesting compound to study in face of the ever-changing parasite. However, being hydrophobic, curcumin has poor oral availability and is rapidly metabolized after administration. These characteristics represent a liability in the pursuit of turning this compound into a successful antimalarial. Synthetic analogues have been reported to improve on these characteristics and have better $\mathrm{IC}_{50}$ values, as low as $400 \mathrm{nM}[43,47]$.

Compound (6) is a catechol derivative known as the main secondary metabolite of the Pothomorphe genus, a group of Brazilian plants used traditionally for malaria $[21,49]$. It has a good activity against the multidrug-resistant strain $\mathrm{K} 1$ (with an $\mathrm{IC}_{50}$ of $0.67 \mu \mathrm{M})$, and it presents low toxicity to mouse $3 \mathrm{~T} 3$ fibroblast cells, with an acute oral $\mathrm{LD}_{50}$ (median lethal dose) in female Swiss mice of $>2 \mathrm{~g} / \mathrm{kg}$ [49]. This compound demonstrated hemolytic properties in human erythrocytes in a wide range of concentrations, which would caution against administration to malaria patients [49]. In vivo toxicity studies demonstrated no death at an oral dose of $2 \mathrm{~g} / \mathrm{kg}$, but changes in mice behavior, such as agitation, reduced water and food consumption, and diarrhea were observed [49]. This could be associated with hemolysis or other types of toxicity that make this compound and its derivatives unlikely antimalarials. Regarding the antiplasmodial activity, catechols are thought to act by their antioxidant activity, possibly through their iron chelating properties or the inhibition of the DNA synthesis, although this is not known with certainty $[40,49]$.

\section{Coumarins and Derivates}

Coumarin, 1,2-benzopyrone, is the basic molecular structure that characterizes this class of compounds. Further modifications may ensue, such as $\mathrm{O}$ - or C-prenylation, cyclization, and other transformations, that may lead to other derivatives, the case of furanocoumarins or pyranocoumarins [30]. These compounds have been the basis for the discovery of some drugs, like warfarin, but are generally known to have limited pharmacological activity [50]. In the case of malaria, the isolated molecules corresponding to the criteria are presented in > Table 2 and Fig. $\mathbf{3 .}$

It is difficult to find highly active antiplasmodial compounds within this class, and there is evidence of a great distinction between sensitive and resistant strains, as evidenced in $\boldsymbol{\nabla}$ Table 2 . However, coumarins have been identified as the active components in some plants used traditionally against malaria $[8,51]$. 
<smiles>CCCCCCC(=O)O[C@H]1c2c(ccc3ccc(=O)oc23)OC(C)(C)[C@@H]1O</smiles>

7

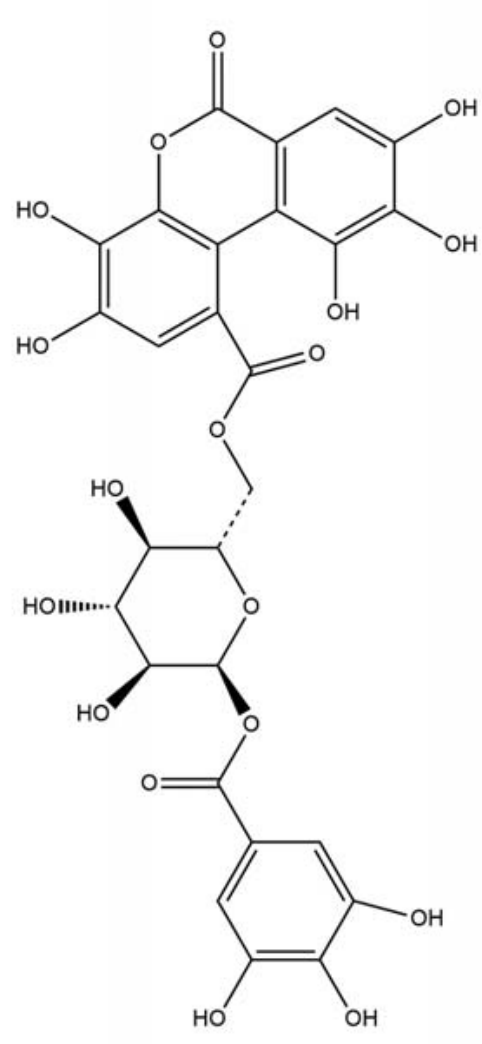

8<smiles>C=CC(C)(C)c1cc2c(O)c3c(c(C(C)(C)C=C)c2oc1=O)OC(C)(C)C=C3</smiles>

9<smiles>CC(C)(O)/C=C/c1cc2c(c3ccc(=O)oc13)OC(C)(C)C=C2</smiles>

10

- Fig. 3 Molecular structures of coumarins and derivatives.

Compound (7) was identified in the rhizome parts of Angelica purpuraefolia Chung, a Korean plant used in folk medicine, after extract tests revealed antiplasmodial activity [52]. Two compounds were isolated and deemed responsible for the extract's activity. Structurally, the difference between (7) and the other compound, ((+)-3'-Decanoyl-cis-khellactone), is the position of the lipophilic chain from carbon $4^{\prime}$ to $3^{\prime}$. This sole change represents an increase in antiplasmodial activity $\left(\mathrm{IC}_{50}\right.$ of $\left.2.4 \mu \mathrm{M} \pm 0.2\right)$ and, consequently, in SI (>62.5) [52]. It could prove useful to study further the structural implications of both compounds in order to establish structure-activity relations.

Compound (8) was isolated and identified from Phyllanthus niruri L., a plant widely distributed in Indonesia with traditional application in malaria [51]. In vitro in the FCR-3 multidrug-sensitive strain, the activity was barely within the interesting range in discussion $(<2 \mu \mathrm{M})$, and unfortunately, no toxicity tests were performed. Microscopical observations detected a stagnation in the ring stage accompanied by morphology changes in the parasite; however, no debate ensued [51]. It is possible to infer that (8) exerts antiplasmodial activity in the early stages, possibly affecting hemoglobin digestion or other metabolomic pathways.

Clausarin (9) was isolated and later identified as one of the antiplasmodial constituents of Clausena harmandiana Pierre, a plant from Thailand [53]. Although its antiplasmodial activity is high $(0.26-1.84 \mu \mathrm{M})$, only 1 strain was tested, and no discussion on toxicity was made [53]. In parallel, another coumarin, dentatin, was also isolated in the same assay. The structural difference between the 2 is an additional prenyl group and an hydroxyl group, instead of a methoxy group [50,53]. This alone represents a 20 fold difference between activities, revealing the importance that the solubility, electromagnetic distribution, and proton availability have in the antiplasmodial activity.

Trans-avicennol (10) was isolated from Zanthoxylum chiloperone var. angustifolium Engl., a tree endemic to central and southern South America, traditionally used to treat malaria [8]. In vitro assays with multiple strains revealed various levels of activity, with the highest effect on the chloroquine-sensitive $\mathrm{F} 32$ strain $\left(\mathrm{IC}_{50}\right.$ of $1.46 \mu \mathrm{M})$ [8]. The compound's toxicity was tested on MCR5 cells and erythrocytes. Results revealed no hemolytic properties and an $\mathrm{IC}_{50}$ of $12.85 \mu \mathrm{M}$ on the MCR5 cells, which does not award the compound a great selectivity toward the parasite [8].

The MoA of this class of compounds is unknown. There is the possibility of formation of adducts with heme, which is the case with trans-avicennol (10) [8]. Whatever the MoA, the presence of hydroxylic groups and carbon chains appears to influence greatly the level of activity. The compound (8), with a gallate moiety, further evidences this structural importance. In any case, it is possible to derive synthetically compounds of interest from this class [52]. 


\section{Flavonoids}

Flavonoids are one of the most abundant and frequently occurring classes of natural compounds. They are broadly present through the entire plant kingdom and, consequently, are consumed daily in the human diet $[4,30,50,54,55]$. The skeleton is based on a ring framework (C6-C3-C6), in which the $A$ and $B$ rings are aromatic and the $C$ ring interconnects both. The connection between the $C$ and $B$ ring differentiates structurally the classes of compounds, likewise with the saturation at $\mathrm{C}-2-\mathrm{C}-3$ or its substitutes $[4,30,55]$. This structure is strongly correlated to the classes' pharmacological activities as anti-inflammatory and antioxidants. Similarly to other phenolic compounds, flavonoids do not usually occur freely but as biflavonoids or glycosides $[4,50,55]$.

As one of the most plentiful secondary metabolites, when plants are analyzed for the possible presence of antiplasmodial compounds, flavonoids are frequently referenced [4]. Following this research, the flavonoids relevant for this review are enumerated in > Tables $\mathbf{3}$ and $\mathbf{4}$ and showed in > Fig. $\mathbf{4}$. Although this phytochemical class proved to be highly active, which at first would be expected, considering its structural diversity, a concept of variety of chemical structures applied to malaria is quickly refuted upon examining the tables. Of the 34 compounds exposed in $>$ Table 3, 25 are flavones and biflavones, 7 are biflavanones, and only 1 other flavanone and 1 flavanolol are present. > Table 4 presents an additional group of 7 catechins with antiplasmodial activities. This demonstrates a preference for the benzo- $y$-pyrone structure and for the connection of the $\mathrm{B}$ ring at the $\mathrm{C}-2$.

The selected flavones appear in 4 forms: glycosides, prenylated, simple, or biflavones. Compounds $(13,15,16,17,18,40$, 41,42 , and 43 ) are all glycosides, with the sugar being either a rhamnose or a glucose. Compound (13) has a rhamnose bonded at the $\mathrm{C}-7$ and all oxygens, namely at $\mathrm{C}-5, \mathrm{C}-6, \mathrm{C}-3^{\prime}$, and $\mathrm{C}-4^{\prime}$, are acetylated, impairing its direct ability to be oxidized. Interestingly, in spite of this, this compound is highly active against both resistant, $\mathrm{IC}_{50}$ of $0.52 \mu \mathrm{M}(\mathrm{K} 1)$, and sensitive strains, $\mathrm{IC}_{50}$ of $0.63 \mu \mathrm{M}$ (NF54) [56]. Comparing it to a similar compound isolated simultaneously but with hydroxylic groups in these positions instead, the activity is also significantly better for (13). Only the SI would be the final indicator on whether this compound could be ideal as an antiplasmodial. Unfortunately, that information could not be found [56]. Compounds (15-18 and 40-43) were isolated from 2 American trees not used traditionally for antimalarial purposes [13]. The first group is bonded to a glucose and the second to a rhamnose at $\mathrm{C}-3$. The most active compounds, both against the sensitive and resistant strain, are (42), (40), and (15). Compounds (15) and (40) have different sugars but are both trans isomers, and considering the coumaroyl moieties, are fairly more active than their cis counterparts. Compound (42) has 1 coumaroyl moiety in cis and another in trans and remains more active against the sensitive strain at an $\mathrm{IC}_{50}$ of $0.50 \pm 0.03 \mu \mathrm{M}$ (HB3) [13]. Besides the activity, the indication of the $\mathrm{SI}$ in this case is very revealing. These 8 compounds are very active in vitro, both against $P$. falciparum and HeLa cells, demonstrating no particular selectivity, a strong prohibitive factor. Compounds (40 and 42 ) represent the exception, but their disparity of activities between strains is also indicative of their limitations [13].
Ten active flavones were isolated from the Artocarpus sp. (Moraceae), a plant traditionally used against malaria in the tropical and subtropical regions of Southeast Asia [57]. The 10 were found to be prenylated but notably only with isoprene groups [57-60]. Compounds (25 and 26) both have an isoprene at C-3 and $\mathrm{C}-8$ respectively. The $\mathrm{B}$ ring differs in 1 oxygen methylation and a cyclization. Despite this, both activities are very close, with an $\mathrm{IC}_{50}$ of 0.12 and $0.18 \mu \mathrm{M}$ in the 3D7 strain, respectively [57]. Artonin A (29), B (34), and F (35) have the same flavone skeleton and 3 structural differences regarding cyclization and isoprene groups [59]. When comparing activities in the same test, the most active compound is (34), with an $\mathrm{IC}_{50}$ of $1.56 \mu \mathrm{M}$ [59]. Considering the sole molecular difference between (34) and (29), with a representative $\mathrm{IC}_{50}$ of $4.9 \mu \mathrm{M}$ in the same assay, it would appear the free hydroxylic group at C-5' is meaningful for activity. Compound (34)'s low SI (5.5), however, puts it at a disadvantage in relation to (35), which is slightly less active, with an $\mathrm{IC}_{50}$ of $2.2 \mu \mathrm{M}$, but also considerably more selective (33.0) [59]. This would lead to the conclusion that the position of the isoprene and the additional ring are important for the selectivity of these compounds. Compounds (27 and 28) further impose the importance of the isoprene group. Compound (28), with an isoprene at C-3, is significantly more active, with an $\mathrm{IC}_{50}$ of $0.66 \mu \mathrm{M}$, than (27), with an $\mathrm{IC}_{50}$ of $1.31 \mu \mathrm{M}$, that includes a ring in that group, leaving free a 2-methylbut-2-ene [58]. Other differences are present in the $B$ ring, but overall it would seem the length of the hydrophobic chain is important. The same occurs between compounds (31 and 32). In this case, the compound with the cyclization at C-3 (31), with an $\mathrm{IC}_{50}$ of $0.02 \mu \mathrm{M}$, is significantly more active than (32), with an $\mathrm{IC}_{50}$ of $1.04 \mu \mathrm{M}$, which has 2 isoprene groups [58]. Lastly, (36) has 3 isoprene groups at C-3, C-6, and C-8 and has an $I_{50}$ of $1.12 \pm 0.08 \mu \mathrm{M}$ [59]. The number of isoprene groups should increase this compound's lipophilia, even with 5 hydroxylic groups available. It would appear that the isoprene group at C-8 is important to increase the lipophilia of the compounds so that they can bypass the cytoplasmatic parasitic membrane and exert additional effects on the parasite $[60,61]$. The most cytotoxic compounds in this group appear to have a isoprene at C-3, which means cyclization at this position might at least decrease toxicity [59]. Moreover, the 10 compounds prove to be strongly antiplasmodial, although not confirmed as selective toward the parasite, questioning the safety of the use of the Artocarpus sp. [57].

Artopeden A (30) is a simple flavone with a C-3 cyclization and with 2 methylations. It may be that the methylations increase its lipophilia enough to have a similar activity to prenylated flavones, since their degree of activity is comparable $\left(\mathrm{IC}_{50}\right.$ of $0.114 \mu \mathrm{M}$ in the 3D7 strain) $[58,61]$. Unfortunately, no further studies are available to discuss this compound's activity. 3',4',7-trihydroxyflavone (23) was isolated from the bark of the Albizia zygia (DC.) J.F. Macbr. tree, traditionally used in Sudan as an antimalarial [62]. Although in the same assay other flavonoids were isolated, sadly no further information regarding in vitro antiplasmodial or cytotoxicity is reported [62]. With a fairly simple chemical structure, with only hydroxyl substitutions at $C-7 / 3^{\prime} / 4^{\prime}$, both good antiplasmodial and cytotoxic results were achieved, which warranted a SI of 5 . The lack of specificity of activity might be connected with 


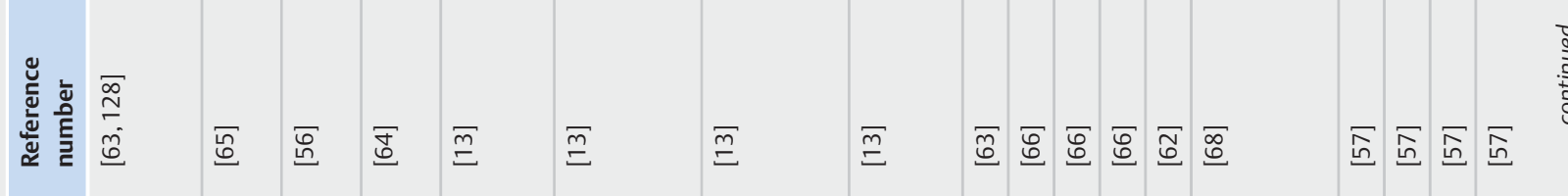

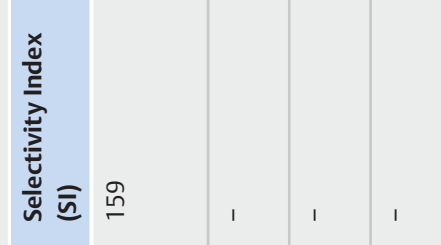

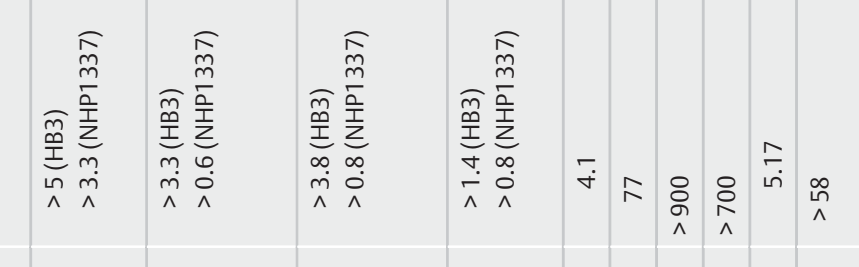

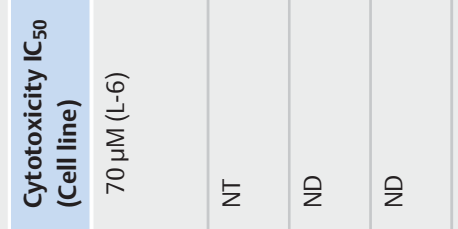

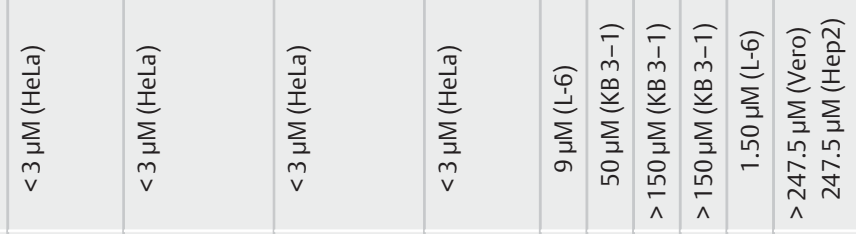

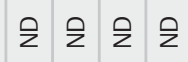

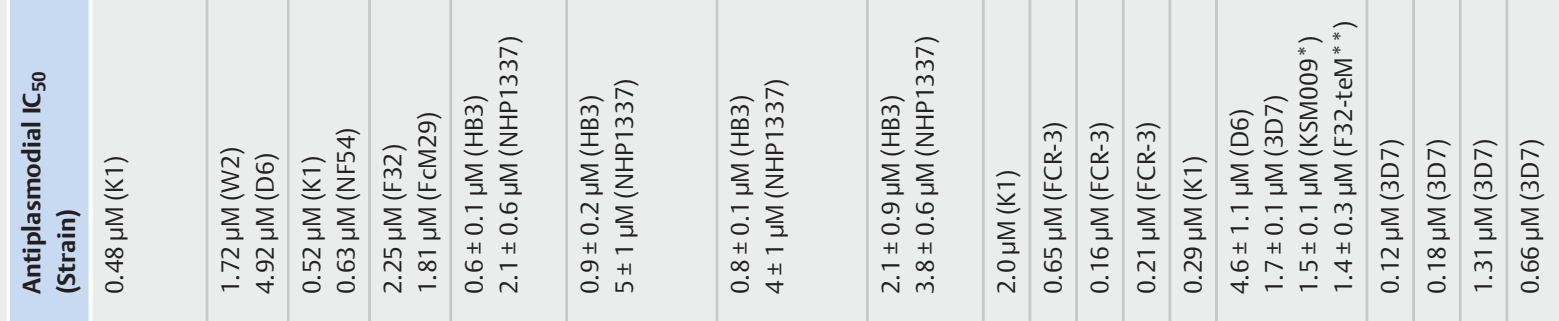

IMU⿴囗十
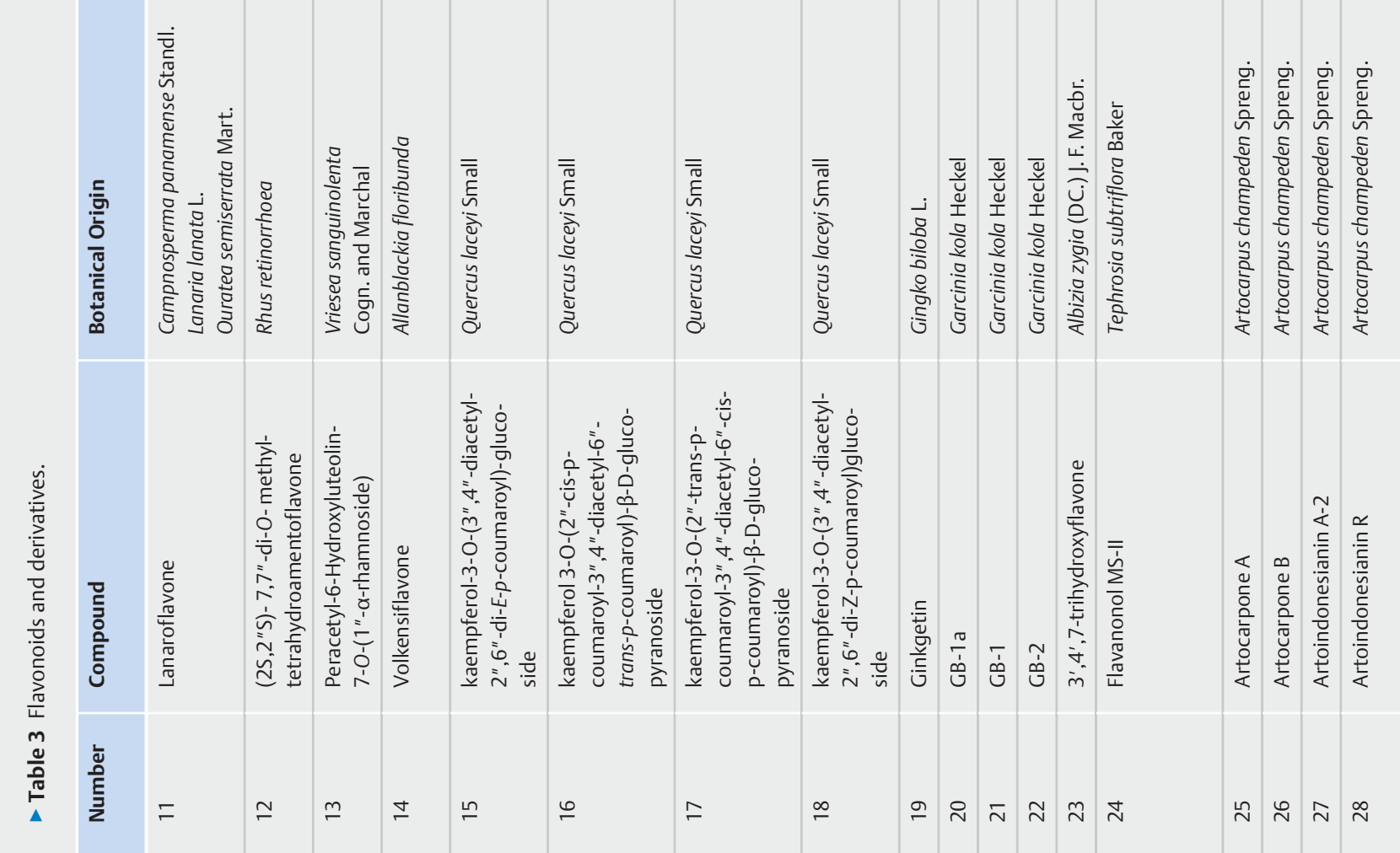


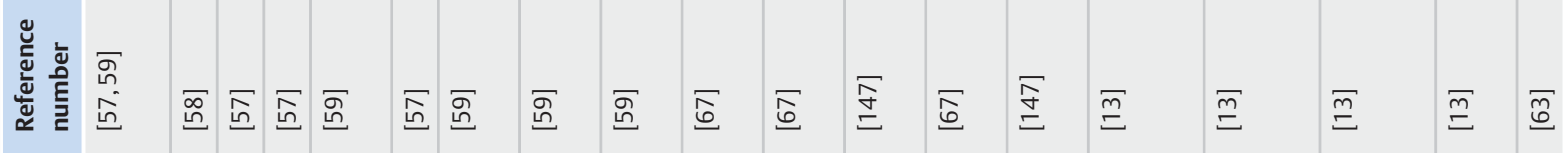

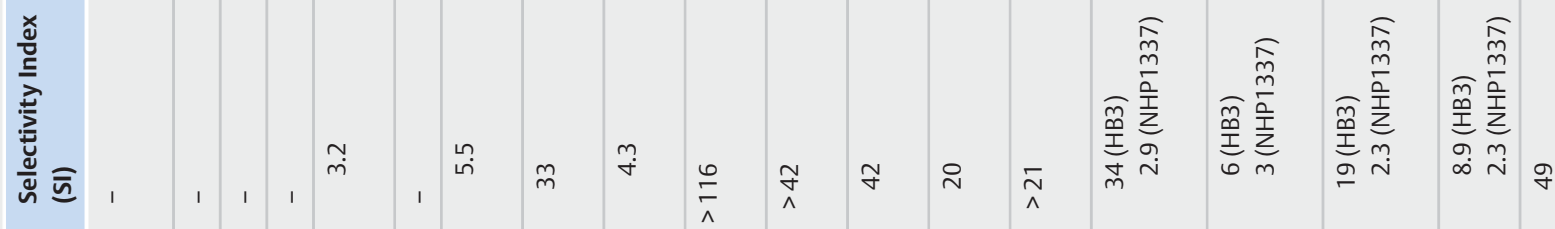
II Mำ \|\|\|\|\|\|\|\|\|\|$\|$ $\mid$
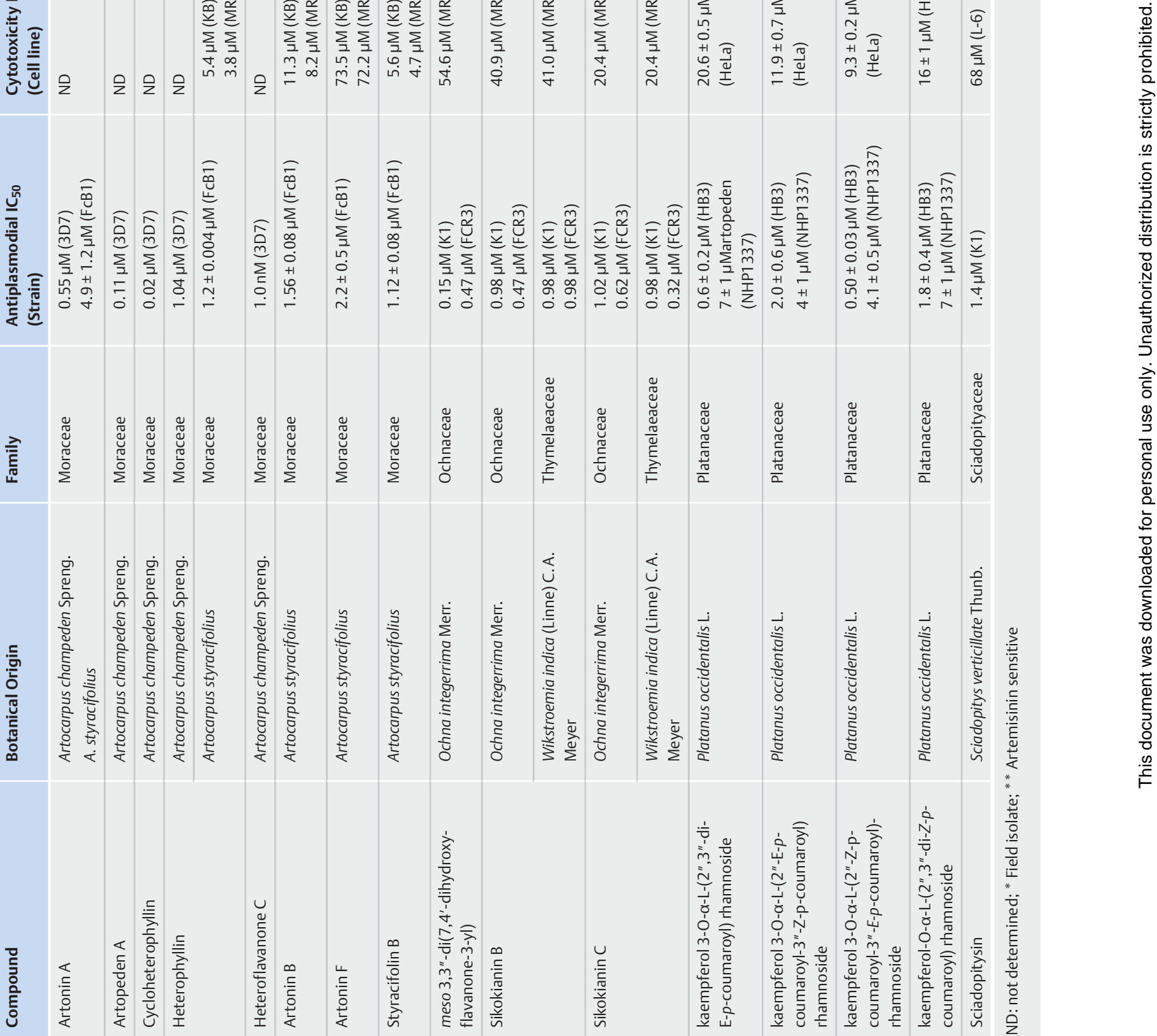
11

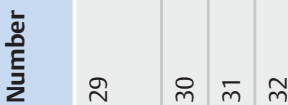

$m \stackrel{m}{m} \stackrel{m}{m} \stackrel{m}{m} \stackrel{\infty}{m}$

우

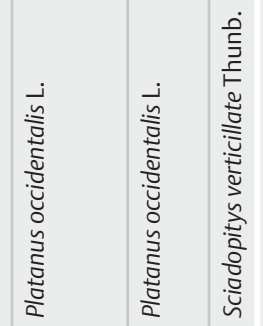




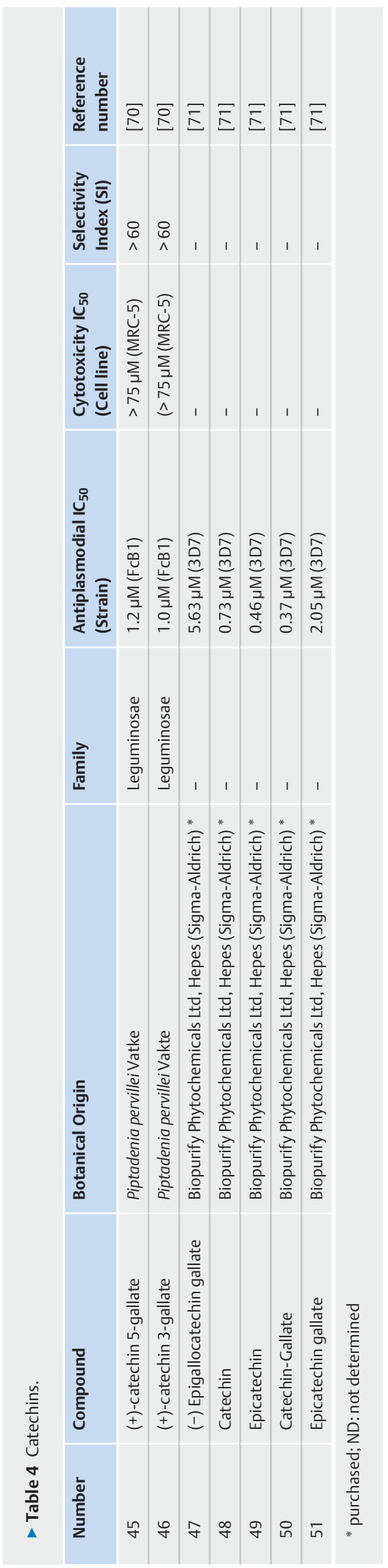

the oxidant potential of this compound, which could be a good starting point to further development.

Biflavones are 2 flavone units, similar or not, connected covalently either through $\mathrm{C}-\mathrm{C}$ or $\mathrm{O}-\mathrm{C}$ bonds, that occur rarely $[50,63]$. Four biflavones were found according to the criteria: compounds (11), (14), (19), and (44). Compound (11) has a C-4"'-O-C-8 bond connecting 2 monomeric similar flavones. Both its activity (IC $\mathrm{C}_{50}$ of $0.48 \mu \mathrm{M})$ and SI (159) are impressive and might be correlated to the bond between the 2 units. In the same study, compounds with a hydroxyl group at C-4"' showed no activity [63]. Compound (14) is an example of a biflavone with 2 different monomeric units, an imposition by the place of the bond between the 2 molecules (at C-3). Similarly, in the same study, it was demonstrated that, if instead of another unit at C-3, the compound had a simple hydroxylic group, the antiplasmodial activity would drop significantly [64]. Although its activity is not as impressive as (11), it demonstrates the possible advantage of biflavones. Compounds (19 and 44) are structurally similar, with the exception of a methylation at the oxygen at C-7 or C-4'. This single difference in their structure is enough to improve the activity of 2.0 and $1.4 \mu \mathrm{M}$, respectively, and, more importantly, the selectivity of (44) over 10 times [63]. The availability of the methoxy group in the $C 4^{\prime}$ position might represent an influence in bonding to specific sites at the human or parasites' cellular structures, enough to prevent a toxic interaction in the host's cells [63]. Overall, the significant $\mathrm{SI}$ of biflavones is interesting toward asserting structural key features.

Only 1 flavanone is relevant in the context of this review: heteroflavanone $C$ (33). Compound (33) is the most active flavonoid, with an $\mathrm{IC}_{50}$ of $1 \mathrm{nM}$ [57]. It has key features that distinguish it from the other compounds discussed thus far. First, it lacks the double bond between C-2-C-3; second, it has only 2 hydroxyl groups; third, the $\mathrm{B}$ ring has 3 oxygens that are all methylated. The availability of the C-3 might be one of the crucial points in the establishment of a bond. Likewise, the methylation of all oxygens on the B ring might improve its lipophilia and allow the compound to enter the parasite more easily. Regrettably, no SI is given, which would complement this compound's profile.

Seven biflavanones are presented: compounds (12), (20), (21), (22), (37), (38), and (39). Compound (12) has improved activity toward the chloroquine-resistant strain [65]. Compounds (2022) were extracted from Garcinia kola sun-dried nuts, which are used traditionally as a chemo preventive of malaria in Central Africa [66]. In vitro tests demonstrated the pertinence of this use: compounds (20-22) exhibited high antiplasmodial activity, I $\mathrm{C}_{50}$ between $0.16-0.65 \mu \mathrm{M}$, and significant selectivity (above 77) [66]. In vivo studies in mice infected with $P$. berghei (ANKA strain) were performed with compound (21) following a 4-day suppressive test [66]. Concentrations ranged from 25 to $200 \mathrm{mg} / \mathrm{kg} /$ day and were orally administered. The mean effective dose (ED $\left.{ }_{50}\right)$ was calculated at approximately $100 \mathrm{mg} / \mathrm{kg}$. The test demonstrated improved mice survivability, no observable toxicity up to $200 \mathrm{mg} / \mathrm{kg} /$ day, and a dose-dependent parasite inhibition [66]. Most importantly, these results were accomplished with an oral administration, which proves to be a great advantage toward developing and studying these compounds further. Compound (37) does not have methylated oxygens and has the bond between the 
<smiles>O=C1c2c(O)cc(O)cc2OC(c2ccc(O)cc2)C1c1c(O)cc(O)c2c(=O)cc(-c3ccc(O)cc3)oc12</smiles>

14

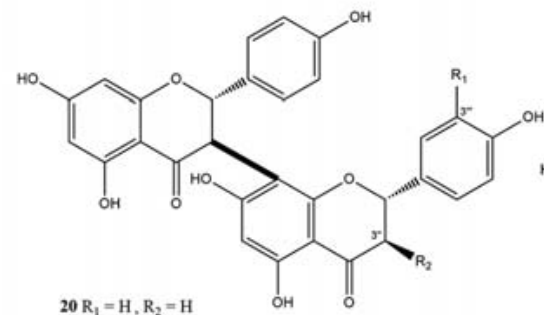

$20 \mathrm{R}_{1}=\mathrm{H}, \mathrm{R}_{2}=\mathrm{H}$ $21 \mathrm{R}_{1}=\mathrm{H}, \mathrm{R}_{2}=\mathrm{OH}$
$22 \mathrm{R}_{1}=\mathrm{OH}, \mathrm{R}_{2}=\mathrm{OH}$<smiles></smiles>

26<smiles></smiles>

30<smiles>COc1cc2c(cc1O)CC(C=C(C)C)Oc1cc(O)c(O)cc1C2=O</smiles>

27<smiles>CC(C)=CCc1c2c(c(O)c3c(=O)c4c(oc13)-c1cc(O)c(O)cc1OC4C=C(C)C)C=CC(C)(C)O2</smiles>

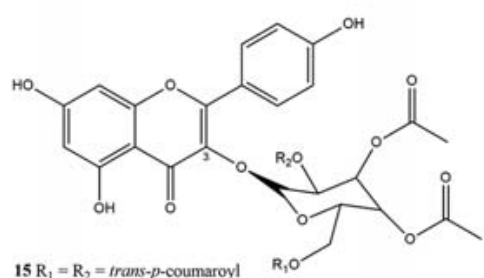

$15 R_{1}=R_{2}=$ trans-p-poumaroyl
$16 R_{1}=$ trans-p-coumaroyl, $R_{2}=$ cis.p-p-coumaroyl $16 R_{1}=$ trans-p-poumaroyl, $R_{2}=$ cis. $p$-coumaroyl
$17 R_{1}=$ cis-p-coumaroyl, $R_{2}-$ trans $-p$-coumaroyl

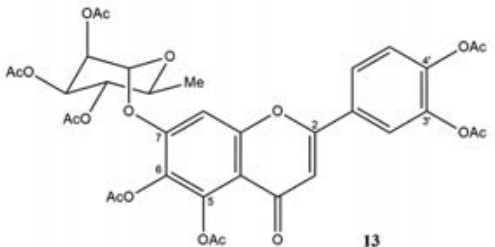<smiles>COc1ccc(-c2cc(=O)c3c(O)cc(O)c(-c4cc(-c5cc(=O)c6c(O)cc(OC)cc6o5)ccc4O)c3o2)cc1</smiles>

$19 \mathrm{R}_{1}=\mathrm{CH}_{3}, \mathrm{R}_{2}=\mathrm{H}$ $44 \mathrm{R}_{1}=\mathrm{H}, \mathrm{R}_{2}=\mathrm{CH}$

- Fig. 4 Molecular structures of flavonoids. (continued) 
<smiles>C=C(C)C1Cc2c(oc3c(CC=C(C)C)c4c(c(O)c3c2=O)C=CC(C)(C)O4)-c2c(O)cc(O)c(O)c21</smiles><smiles>C[C@]1(c2ccc(O)cc2)Oc2cc(O)ccc2C(=O)[C@]1(C)[C@H]1C(=O)c2ccc(O)cc2O[C@H]1c1ccc(O)cc1</smiles>

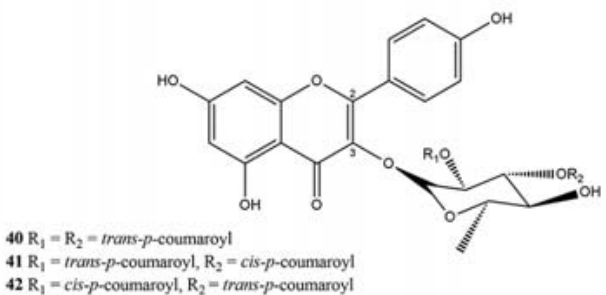
$41 R_{1}=$ trans $-p$-coumaroyl, $\mathrm{R}_{2}=$ cis-p-coumaroyl
$42 \mathrm{R}_{1}=$ cis-p-coumaroyl, $\mathrm{R}_{2}=$ trans - - - coumaroyl $42 R_{1}=$ cis-p-coumaroyl, $R_{2}=$ -
$43 R_{1}=R_{2}=$ cis-p-coumaroyl<smiles>Oc1cc(O)c2c(c1)O[C@H](c1ccc(O)c(O)c1)[C@H](O)C2</smiles><smiles></smiles><smiles>COc1ccc([C@]2(C)Oc3cc(O)ccc3C(=O)[C@]2(C)[C@H]2C(=O)c3c(O)cc(O)cc3O[C@]2(C)c2ccc(O)cc2)cc1</smiles><smiles>CC(=O)c1cc(O)c(O)c(O)c1</smiles><smiles>O=C(O[C@H]1Cc2c(O)cc(O)cc2OC1c1ccc(O)c(O)c1)c1cc(O)c(O)c(O)c1</smiles>

50<smiles>CC(C)=CCCc1c(-c2cc(O)c(O)cc2O)oc2c(CC=C(C)C)c(O)c(CC=C(C)C)c(O)c2c1=O</smiles><smiles>COc1ccc([C@]2(C)Oc3cc(O)cc(O)c3C(=O)[C@@]2(C)[C@H](C)[C@@]2(C)Oc3cc(O)cc(O)c3C(=O)[C@@]2(C)c2ccc(O)cc2)cc1</smiles><smiles>O=C(O[C@H]1Cc2c(O)cc(O)cc2OC1c1cc(O)c(O)c(O)c1)c1cc(O)c(O)c(O)c1</smiles>

47<smiles>O=C(O[C@H]1Cc2c(O)cc(O)cc2OC1c1ccc(O)c(O)c1)c1cc(O)c(O)c(O)c1</smiles>

- Fig. 4 Continued

C rings, C-3-C-3". Compounds (38 and 39) have the same bond as (37) but a methylated oxygen at C-4' or C-4"', respectively. Between (38 and 39), there's the additional difference in isomerism of the protons at $\mathrm{C}-3^{\prime \prime}$. In the same tests, compound (37) was the most active, with an $\mathrm{IC}_{50}$ of $0.15 \mu \mathrm{M}(\mathrm{K} 1)$ and $0.47 \mu \mathrm{M}$ (FCR-3), and selective (>116) of the 3 [67]. This demonstrates that the occupation of the $\mathrm{C}-3$ of the flavanone by another unit is not a disadvantage toward activity or selectivity.

Flavanonol MS-II (24) is a flavanolol with 2 (2,2-dimethylchromene) rings. In spite of having been solely tested on sensitive strains, it demonstrates a relevant variety in activity depending on the strain (see - Table 3) [68]. Its selectivity toward the parasite is noteworthy, proposing that resistant strains should be tested in order to assess the compound's potential.

Lastly, catechins are a particular sub-group of flavonoids, distinguishable by the absence of the carbonyl group on the C-ring [30]. They are abundantly found in green tea leaves (Camellia sinensis) as acid esters and are known for their antioxidant properties $[4,69]$. Hence, these compounds are frequently isolated with their gallate moieties, as evidenced in $>$ Table 4 . Compounds (45 and 46) are 2 catechins active against a chloroquine-resistant strain, with an $\mathrm{IC}_{50}$ of 1.2 and $1.0 \mu \mathrm{M}$, respectively, and with a re- 
markable SI (> 75). They differ solely on the position of the gallate moiety, either at C-5 or C-3, respectively. However, this does not seem to interfere with either their activity or selectivity; on the contrary, the existence of the gallate esters seems essential toward their inhibitory activity, independently of the positioning [70]. Compounds $(48,49$ and 50,51$)$ are structurally related, differing only on the isomerism at C-2 and C-3. Studies specifically targeting the fatty acid synthesis (FAS) have demonstrated the structural requirements for the parasiticidal effect through FAS inhibition. Catechins with a gallate moiety at C-3 are all potent inhibitors, while a free single hydroxyl group in the same position seems to greatly diminish this activity [55]. Consequently, catechins (50 and 51) may act through this mechanism. The gallate substitution in these compounds appears crucial for their inhibitory activity, especially considering that gallic acid alone is inactive $[33,55,71,72]$.

Compound (47) has other properties that might award it an additional edge against malaria. The epigallocatechin gallate (47), a catechin with both a galloyl and a gallate moiety, is the most studied, with reported activity against tumor cells and as a cell cycle regulator $[69,72]$. It binds to adhesion molecules, preventing the grip of $P$. falciparum-infected erythrocytes to the endothelium of blood vessels [69]. Additionally, it inhibits the gliding motility of sporozoites, preventing invasion and interrupting the parasite's cycle [69]. It is possible that its 8 free hydroxylic groups bind to adhesion molecules on the surface of the sporozoites, inactivating them and rendering the parasite immotile [69]. However, in spite of these demonstrated advantages in vitro, in vivo data reveals otherwise. In a 4-day suppressive test with $P$. berghei (ANKA strain)-infected mice, concentrations between 0-100 mg/ $\mathrm{kg} /$ day of (47) equivalent in the form of green tea extract were administered by gavage [73]. Instead of inhibiting, the administration of the extract augmented the parasite's growth over the control's own growth [73]. Thipubon et al. discuss that the compound's (47) highly antioxidant activity might prevent the oxidative damage by the mice's immune system, consequently endorsing the parasite's growth. However, there are various studies that support either the suppression or promotion of $P$. berghei by compound (47), which prevents the deduction of conclusions $[55,71$, 73].

Several studies have been performed in order to assess the MoA of flavonoids. There are 3 main ways they interfere with the malaria parasite. First, it is thought they inhibit the transport of substances necessary for the parasite's growth; second, they might affect heme detoxification; third, as mentioned for catechins, flavonoids inhibit lipid peroxidation [4, 50, 54, 74-76]. The entry of L-glutamine and myoinositol into infected red blood cells is impaired in the presence of flavonoids $[4,77]$. The way flavonoids might interfere with heme is not entirely clarified, since their acidic nature, although weak, might prevent their entry in the digestive vacuole, where the heme is [4]. Flavonoids are demonstrated radical scavengers that bind easily with metals, specially iron, and are able to form stable complexes with Fe (II), therefore preventing it from partaking in other reactions, such as DNA synthesis and energy-enzymatic pathways, possibly starving the parasite $[4,54,74,76,78]$. Theoretically, and similarly to synthetic iron chelators that have been studied toward $P$. falciparum, flavo- noids might also interfere with mosquito transmission [78]. Since iron is a key-component in the function of the gametocyte's mitochondrial electron transport chain, chelation is thought to inhibit this system, thus inactivating the gametocyte [78]. Transmission tests with flavonoids would have to be performed to confirm this. Structure-activity studies demonstrated that an o-hydroxyl on the $B$ ring of a flavonoid, the number of free hydroxyl groups, and the double bond at C-2-C-3 or a C-3 hydroxyl group all contribute to these activities $[4,54,74]$. All presented compounds possess 1 or more of these characteristics, imposing the possibility of antiplasmodial activity through multiple mechanisms. Moreover, this flexibility regarding structure is in accordance with the evidence that many structurally diverse flavonoids have antiplasmodial activity in a wide range of concentrations [50]. In addition, the FAS of the parasites, and to some level, of the host, are inhibited by these compounds $[55,77]$. The di- and tri-hydroxylation of the $B$ and A ring and the double bond at C-2-C-3 (flavanols, isoflavanols, flavones, isoflavones) are common features of the most potent inhibitors $[50,55,72]$. This evidences the importance of both the planarity of the C-ring and the availability of hydroxylic groups at the B-ring toward antiplasmodial activity [55]. Compounds such as $(15-18,31,32,34,36,40-43)$ fit these characteristics. Catechins might have other characteristics, like the gallate moiety, to favor their inhibition of this biosynthetic pathway, as discussed above. However, it is noteworthy that the most active compounds presented are not the ones with a di- or tri-hydroxylation of the $B$ ring but with prenylations of this ring. This ultimately leads to the conclusion that the compound's lipophilia is crucial for activity, even if only to facilitate the entrance into the parasite.

Flavonoids are known for their low toxicity to humans, with interesting half-lives that can go up to $28 \mathrm{~h}$ [55]. Additionally, their solubility and thermostability convey favorable pharmacokinetic characteristics relevant for a possible antimalarial drug, especially considering their dietary presence $[4,55]$. Further studies concerning the $\mathrm{SI}$ and with differentiated strains might help elucidate the potential of these compounds as future antimalarial drugs.

\section{Quinones, Anthrones, and Derivatives}

Quinones are products of the oxidation of phenolic compounds, and they occur widely in plants [30]. The quinone unit is a 6-carbon diene cycle with 2 keto groups, o-quinone or $p$-quinone. These units can group and are distinguished according to their structure as anthraquinones, benzoquinones, furanoquinones, and naphthoquinones, among other derivatives $[30,50]$. It is noteworthy to mention that quinones undergo reduction to the hydroquinone form, an important property in the transferal of electrons in a biological system [30]. Natural quinones, and naphthoquinones in particular, are a phytochemical class with known parasiticidal activity [3]. In malaria's case, a good example is atovaquone, a synthetic derivative of lapachol from the Tabebuia sp., used in combination with proguanil in Malarone, recommended for travelers' prophylaxis $[3,13,15]$. Thirty compounds were found on the literature according to the defined criteria across all subgroups of quinones. They are presented in $>$ Table $\mathbf{5}$ and Fig. 5. 


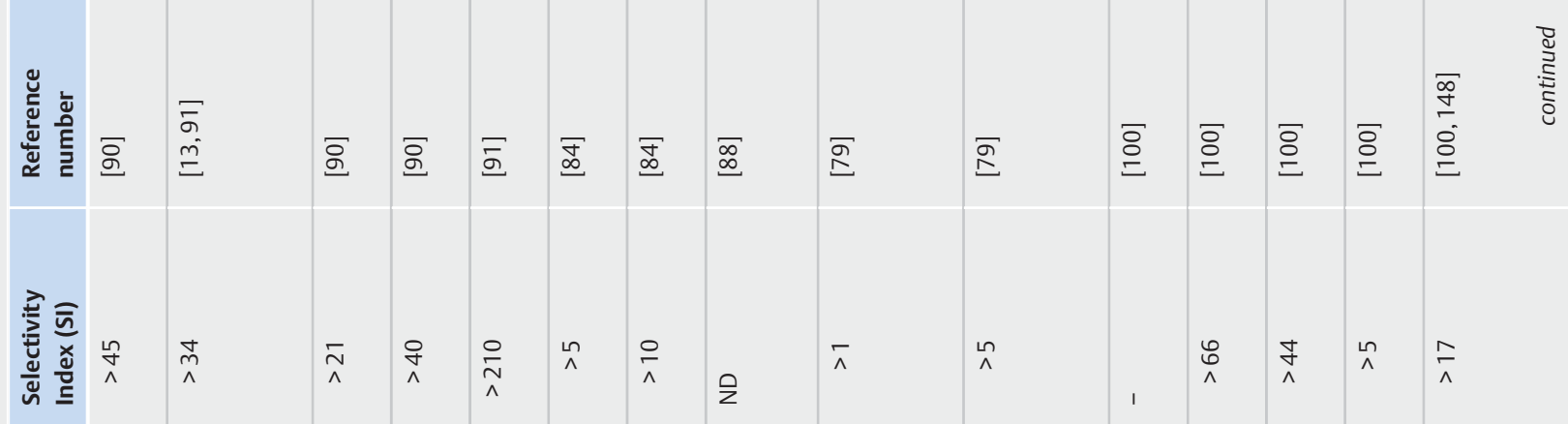

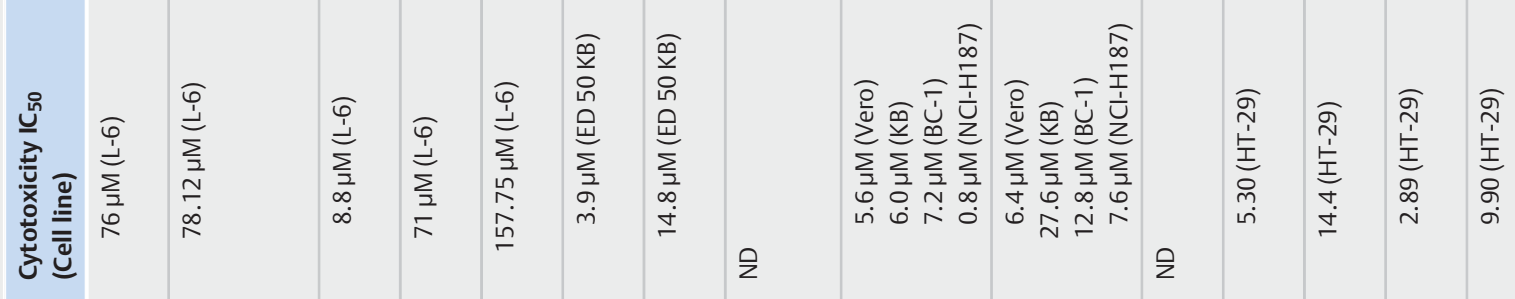

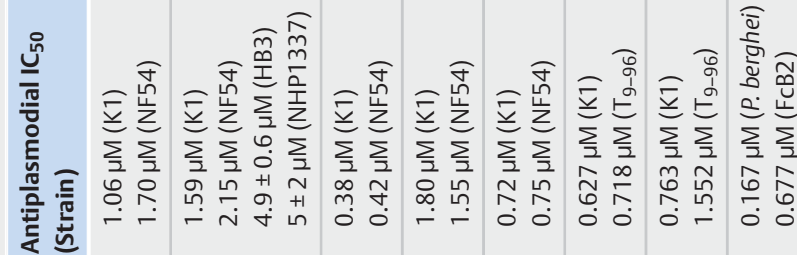

衰咅咅

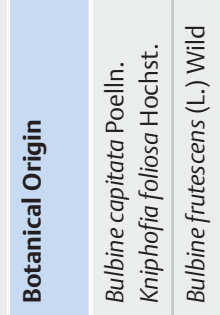

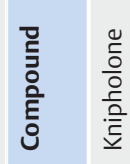

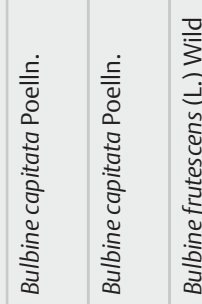

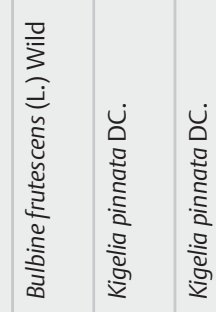
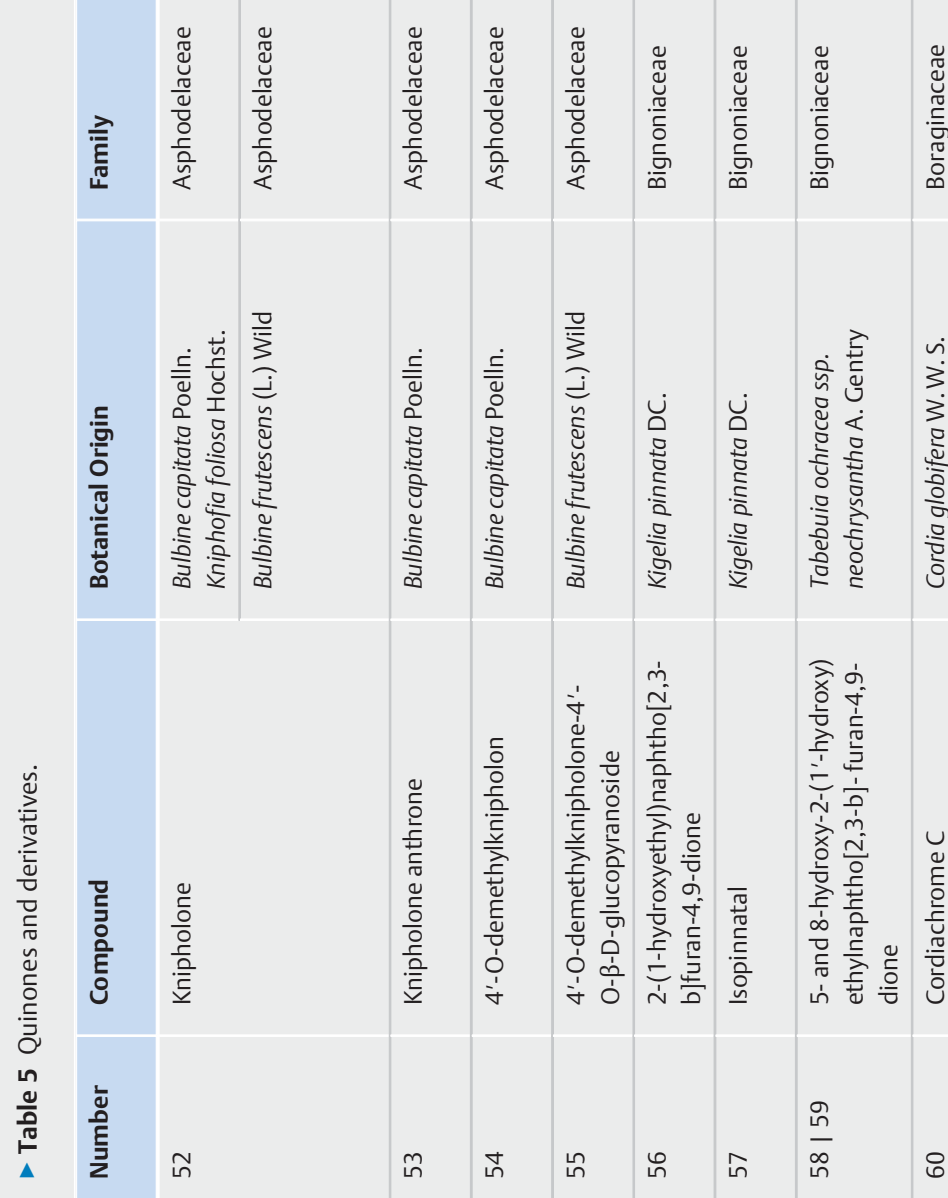

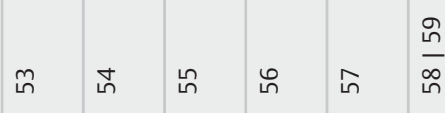

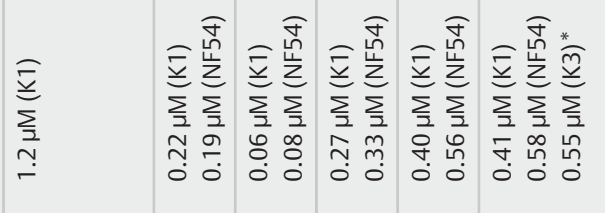

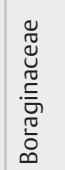
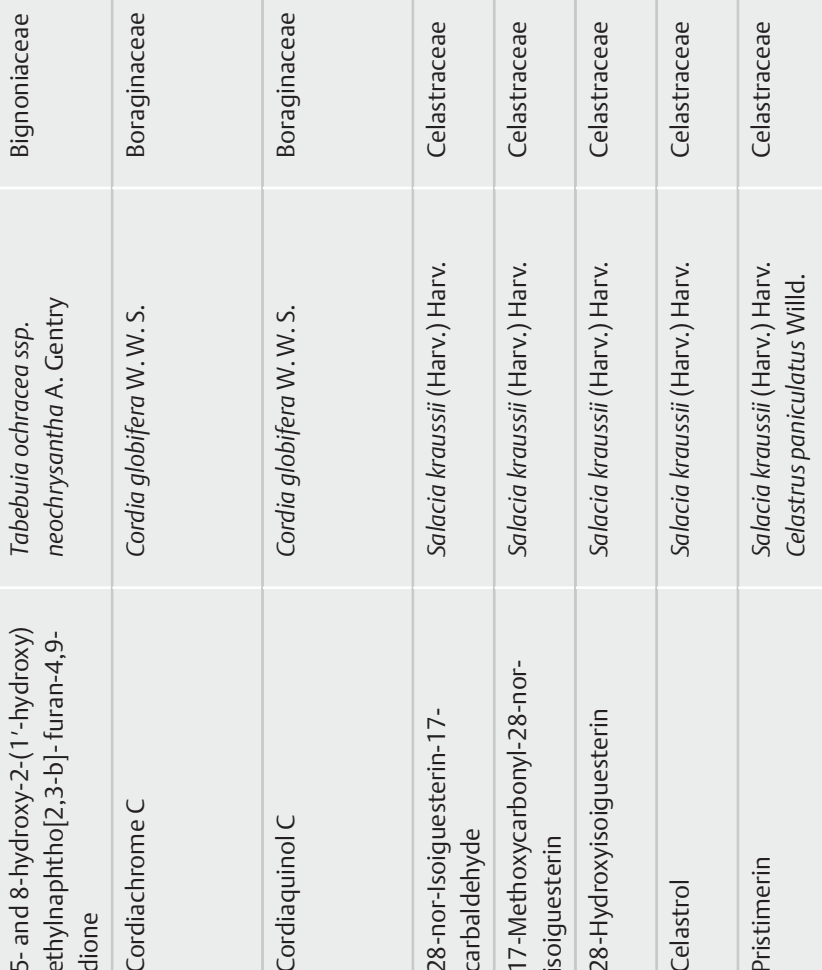


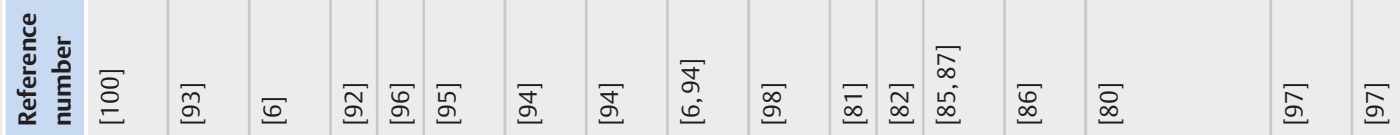

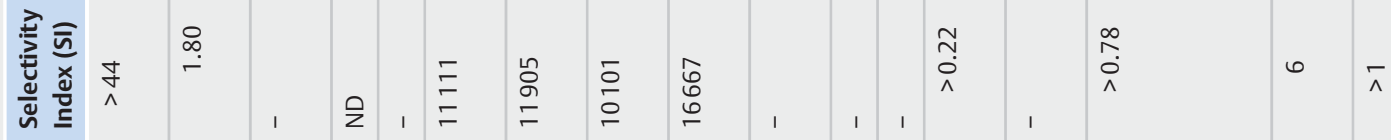

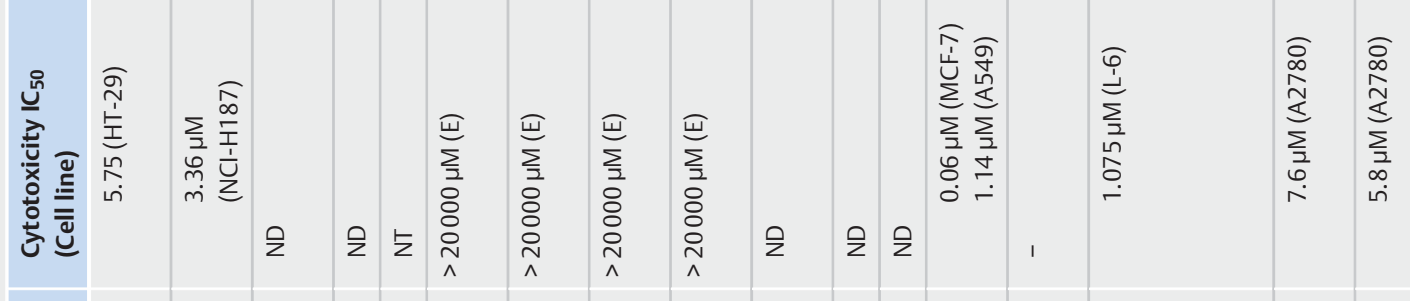

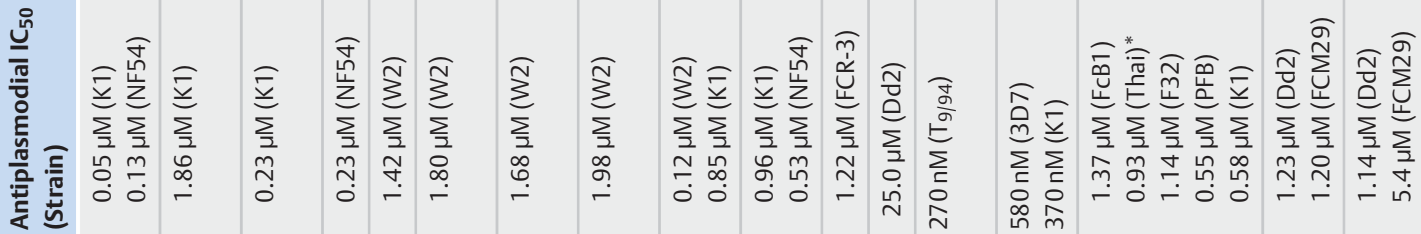

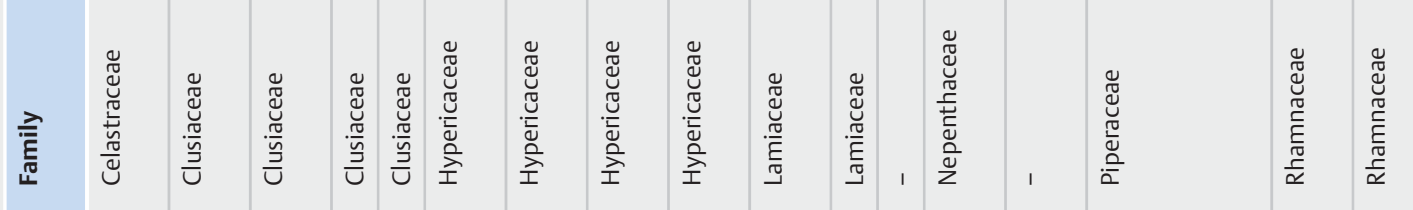

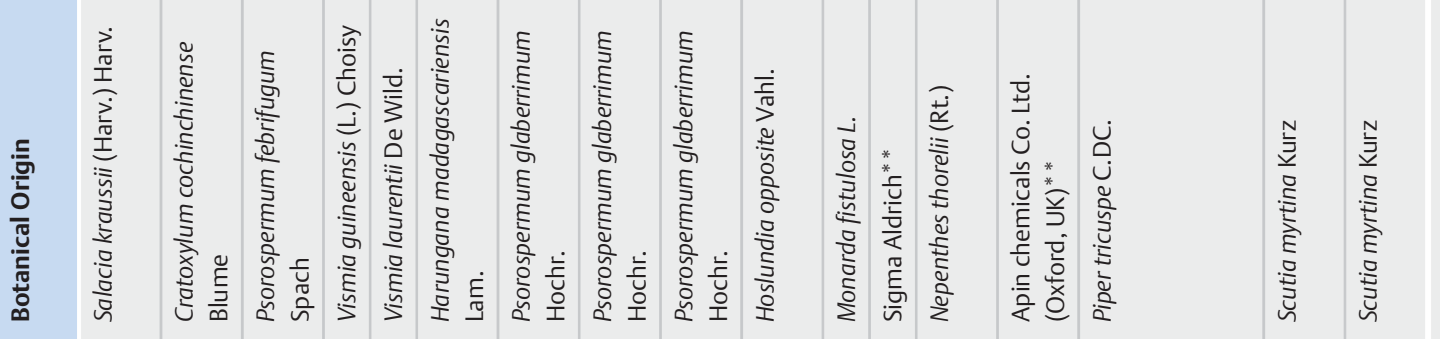

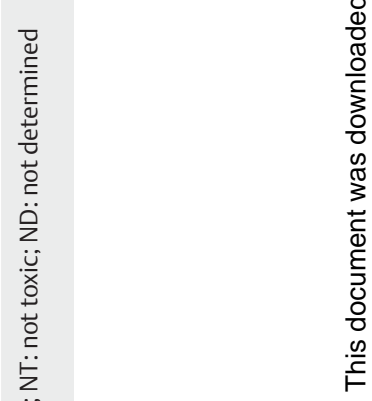

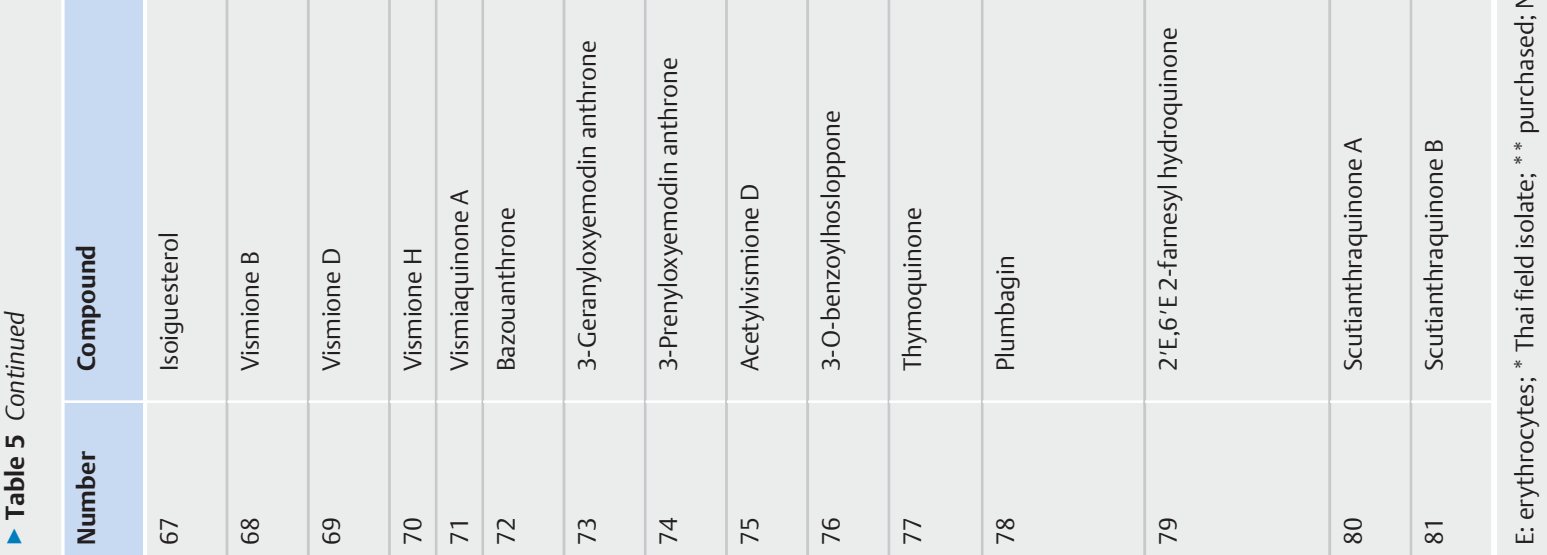




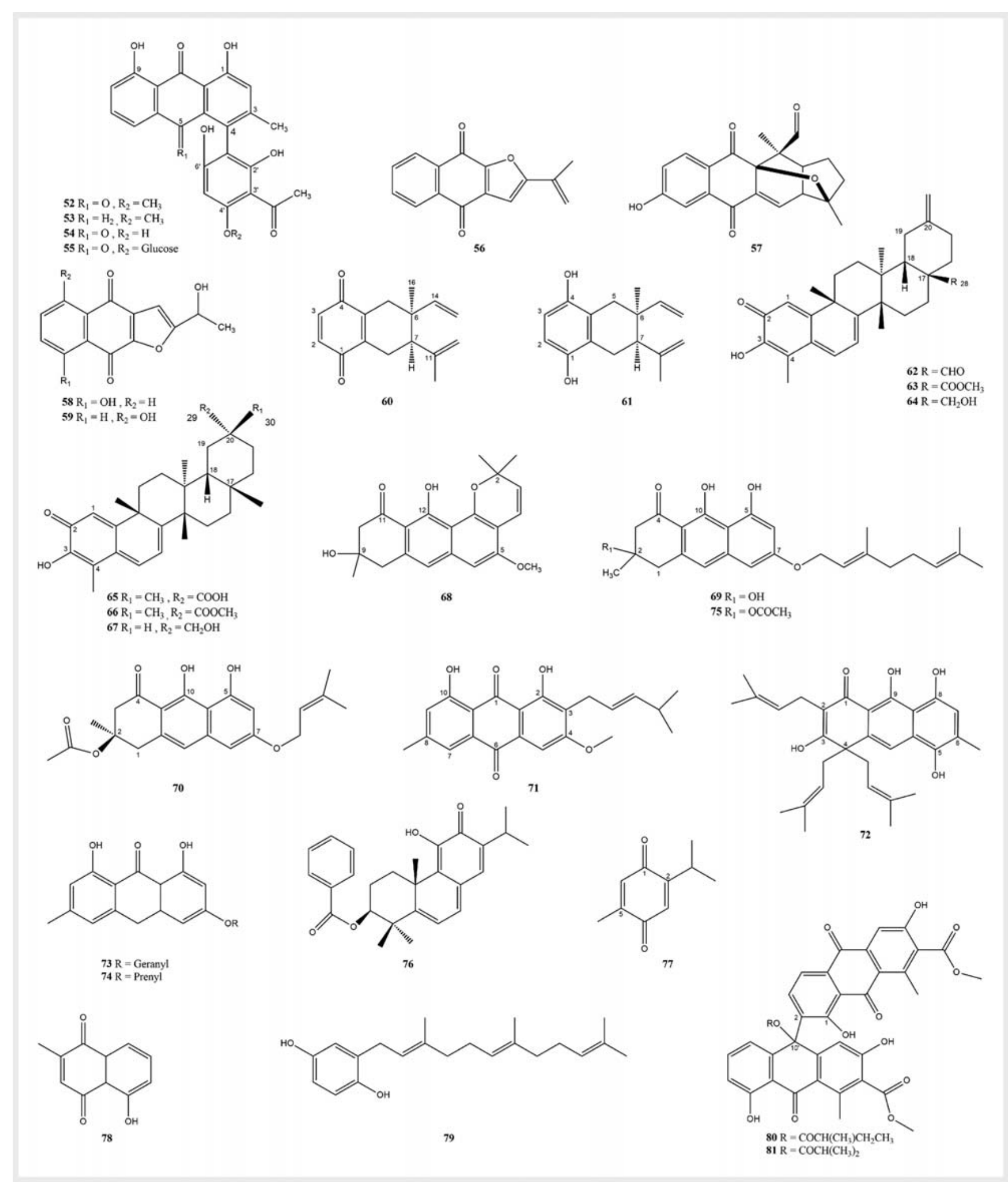

- Fig. 5 Molecular structures of quinones.

Benzoquinones are defined by the presence of the quinone unit with a single ring. In total, 4 compounds have this structure. Compound (60) is an active quinone with an $\mathrm{IC}_{50}$ of $0.8 \mu \mathrm{M}$, with low selectivity $(>1)$ that can undergo a redox reaction and convert to a hydroquinone, compound (61). This transformation does not prove useful toward $P$. falciparum, diminishing its activity to $1.2 \mu \mathrm{M}$ and maintaining its low selectiveness (>5) [79]. Compound (79) is a hydroquinone with a long carbon chain. It is be- 
lieved its free hydroxyl groups and benzene ring grant its activity, although the chain's lipophilia surely contributes to the entry in the parasite [80]. Thymoquinone (77) is a benzoquinone that was isolated from multiple plant species with antimalarial traditional backgrounds $[81,82]$. In a first report, its antiplasmodial activity against a multidrug-sensitive strain (FCR-3) was relevant $\left(\mathrm{IC}_{50}\right.$ of $\left.1.22 \mu \mathrm{M}\right)$ [81]. Since then, further studies have focused on the anticancer and antitumor potential of the compound [83]. One study reported on the synthesis of analogues toward both ovarian cancer and malaria in vitro [82]. Structure-activity studies revealed that the position of the substitution groups in the quinone moiety proved essential, as did the hydrophobicity of the compound, with the chain substitution diminishing the antiplasmodial activity. Overall, in this study, compound (77) displayed a disparate inhibitory concentration of $25 \mu \mathrm{M}$, and the optimization of the molecule's structure improved this concentration only to $4.2 \mu \mathrm{M}$, which is still far from ideal [82].

Naphthoquinones, related to natural naphthalene, have a quinone unit coupled with an aromatic ring that may have substitutions, in a total of 2 rings. Compounds (57 and 78) both fit this description. Compound (57) has a hydroxyl substitution in its aromatic ring and the particularity of an endoperoxide bridge. It shows an improved activity toward a multidrug- resistant strain, with an $\mathrm{IC}_{50}$ of $0.76 \mu \mathrm{M}(\mathrm{K} 1)$, rather than the sensitive one, with an $\mathrm{IC}_{50}$ of $1.55 \mu \mathrm{M}$, with an average selectivity (> 10) [84]. Compound (78), isolated from a traditionally used plant, has an interesting antiplasmodial activity across different strains but unfortunately, no selectivity [85]. In vivo studies with pure (78) orally administered were performed in a $P$. berghei model (ANKA strain) in a 4-day suppressive test [86]. Interestingly, acute toxicity assays were also done with single oral doses of 500,200 , and $100 \mathrm{mg} /$ $\mathrm{kg}$ body weight, and subacute assays with oral doses of 100, 50, and $25 \mathrm{mg} / \mathrm{kg} /$ day for 14 days. Low toxicity was achieved at $100 \mathrm{mg} / \mathrm{kg}$ in a single dose and $25 \mathrm{mg} / \mathrm{kg} /$ day for 14 days. In spite of no histological damage, behavioral changes, such as anxiety and agitation, were evident, and mice died with a single dose of $200 \mathrm{mg} / \mathrm{kg}$ or higher, or cumulative doses of $100 \mathrm{mg} / \mathrm{kg} /$ day or higher [86]. These results are indicative of the unideal SI. As for the antimalarial test, a concentration of $25 \mathrm{mg} / \mathrm{kg} /$ day resulted in a $41 \%$ parasitemia suppression at day 4 with an average survival of 10 days [86]. These results are far from the control chloroquine, with $100 \%$ suppression and over 15 days survival at $10 \mathrm{mg} / \mathrm{kg} /$ day. The low oral bioavailability of (78) produces only $39 \%$ systemic availability, while mostly being retained in the liver and spleen [86]. Therefore, arguably, its bioavailability could change the in vivo outcome, both in toxicity and efficiency.

Structure-activity studies with both compounds (57 and 78) undeniably confirmed the quinone structure was crucial for antiplasmodial activity, while substitutions at C-3 were detrimental $[19,84,87]$. In spite of the low SI of naphthoquinones, authors defend the selectivity toward cancerous cells and the parasites' mitochondria, and not normal hosts' cells [84]. Additionally, (78) is a ubiquinone analogue and has demonstrated its inhibitory activity against malarial enzymes [86]. Regardless of these arguments, naphthoquinones represent a lead in antimalarial research because they are easily synthetized, which enables the improve- ment of their bioavailability and facilitates the search of new drugs [50].

Furanoquinones are a diverse group of compounds where a quinone unit and a furan ring are present. Compound (56) is a furanonaphthoquinone, because in addition to the other structures, it possesses an aromatic ring, characteristic of a naphthoquinone. It demonstrates no significant difference in activity between chloroquine-sensitive and -resistant strains and, similarly to naphthoquinones, has a low SI (3.9) [84]. Likewise, compounds (58 and 59) are also furanonaphthoquinones, this time inseparable compounds extracted from the stem bark of Tabebuia ochracea ssp. A. Gentry, traditionally used against malaria [88]. In vitro assays demonstrated a preferentiality in activity toward the chloroquine-resistant strain. The alternate hydroxylation at C-5 or C-8 proves more advantageous than the hydroxylation in both positions [88]. Regrettably, the general toxicity of these compounds was not evaluated. In an in vitro test with $P$. berghei-infected cells, these compounds had an $\mathrm{IC}_{50}$ of $0.167 \mu \mathrm{M}$, allowing the prediction of good activity in vivo [88]. These 3 compounds demonstrate the benefit of associating the furan ring to the naphthoquinone structure, possibly instigating a new class of antimalarials.

Anthraquinones are frequent metabolites with a 3-ring skeleton, namely 1 quinone unit and 2 aromatic rings. They can be oxidized or reduced into derivatives in reversible reactions, and the ratio between these structures in a plant depends on several factors, for example, the time of the $y$ [30]. Because they react easily, the method of extraction is important to control the ratio and kind of compounds extracted [30]. This phytochemical class has presented the biggest amount of antiplasmodial compounds, revealing its importance to traditional medicine.

Knipholone (52) is an anthraquinone pigment found in at least 30 plants, with several known derivatives $[89,90]$. Compound (53) is the anthrone derivative of (52); (i.e., through reductions), it loses the ketone at C-5. This change is enough to double the antiplasmodial activity, from over $1 \mu \mathrm{M}$ to $0.4 \mu \mathrm{M}$, while its selectivity worsens significantly, from over 34 to 21 [90]. Compound (54) is similar to (52), but instead of an O-methyl at C-4', it has a hydroxyl. This difference does not change the selectivity $(>40)$ or activity toward the chloroquine-sensitive strain (of $1.55 \mu \mathrm{M}$ ) but diminishes the activity against the multi-drug-resistant strain ( $\mathrm{IC}_{50}$ of $\left.1.80 \mu \mathrm{M}\right)$, indicating the necessity of a hydrophobic chain at that position against a specific resistance mechanism [90]. Compound (55) is another knipholone derivative, again with a sole difference at C-4', with a glucopyranoside. Contrarily to (53), compound (55) improves both its antiplasmodial activity $\left(\mathrm{IC}_{50}\right.$ of $\left.0.7 \mu \mathrm{M}\right)$ and selectivity (> 210) with this change, showing the relevance of the substitution at C-4' [91]. Knipholones' antiplasmodial properties seem to be rooted in the special phenyl-anthraquinone skeleton, since neither structure individually has any significant activity $[90,91]$.

Vismiones are lipophilic anthrones originally isolated from the Vismia sp., traditionally used against malaria $[6,92]$. Other derivatives have been isolated in different species since and revealed the exceptional antiplasmodial activity associated with these compounds' structure. Vismione B (68), D (69), H (70) and acetylvismione $\mathrm{D}(75)$ are all molecularly related, with changes at C-2/9 and C-7. Additionally, (68) has a dimethyl chromene moiety. 
Although in separate tests, compounds $(69,68$, and 75$)$ were all tested in vitro on the $\mathrm{K} 1$ strain. Compound (69) is more active than (75), both better than (68) on this strain, with $\mathrm{IC}_{50}$ of $0.23 \mu \mathrm{M}$, $0.85 \mu \mathrm{M}$, and $1.86 \mu \mathrm{M}$, respectively $[6,93,94]$. The fact that $(70)$ remains highly potent on a different strain $\left(\mathrm{IC}_{50}\right.$ of $0.23 \mu \mathrm{M}$ in the NF54 strain) allows the conclusion that either a prenyl or a geranyl group at C-7 are equally essential for antiplasmodial activity [92, $94,95]$. Regarding selectivity, however, compound (75) is the only selective and safe compound [6,94]. Inclusively, Psorospermum febrifugum Spach, with compound (69), has been ill advised for consumption following reports of toxicity in mice [6].

Vismiaquinone $A(71)$ and compound (72) are anthrones similar to vismiones, with minor differences in their substitutions. Overall, the number of hydroxyl groups is higher. Unfortunately, the strains studied are not the same, which does not allow a comparison, but other compounds in the same study permit further structure analysis. It would appear that the prenyl group at C-2 and the hydroxyl at C-5 are enhancers of activity, although it is uncertain if they function additively or synergistically [95]. On the same study, compound (72) was the most potent antiplasmodial, possibly because it is a tri-prenylated anthrone [95]. Additional studies would have to be performed to analyze how these characteristics influence the activity of vismiones and anthrones. Regarding (71), because in the same study other related compounds were not tested, it is not possible to infer structure-activity links. However, from this family of compounds, it would seem safe to conclude that the quinone substitution interferes with activity and that the substitution with increasingly lipophilic chains might also improve antiplasmodial activity [96].

Compounds (73 and 74) are anthrones isolated from the root bark extract of Psorospermum glaberrimum Hochr., used traditionally for severe cases of malaria [94]. Their sole structural difference is an O-geranyl or prenyl at C-4, which does not seem to interfere with either the activity or selectivity. It would appear, though, that anthrones with their chemical unit on an extremity are preferred activity-wise, when comparing these 2 compounds with vismiones [94].

Scutianthraquinone $A(80)$ and $B(81)$ are anthraquinones with the particularity of having a connection $\mathrm{C}-2-\mathrm{C}-10^{\prime}$ to an anthrone, which is a rare structure. This precise characteristic conveys better activity than a simple hydroxyl substitution [97]. Unfortunately, the selectivity is not optimal, and the complexity and rarity of this chemical structure hinders further studies with these compounds [97].

Finally, natural quinone methides triterpenes exist in nature as quinone derivatives. Compound (76) was isolated from Hoslundia opposita Vahl., a traditionally used plant against malaria in Tanzania [98]. It is a hydroquinone with a sesquiterpenoid sidechain, with its $\alpha, \beta$-unsaturated carbonyl moiety possibly responsible for a Michael reaction with the parasites' structures [98]. This is, however, unlikely, as this reaction has been shown to occur more intensively with simple benzoquinones (1,4-benzoquinone) or naphthoquinones [99]. Compounds (62-67) were isolated from Salacia kraussii (Harv.) Harv. and were found to have interesting activities. Compounds (62-64) have only a different substitution at C-28 sufficient to distinguish, and (63) has the most active, with an $\mathrm{IC}_{50}$ of $0.06 \mu \mathrm{M}$ in the $\mathrm{K} 1$ strain and $0.08 \mu \mathrm{M}$ in the
NF5684 [100]. Likewise, compounds (65-67) have 2 different substitutions at C-29 and C-30, enough to ascertain (67) as the most active and selective of the trio but not of the entire group. Compound (63), the most active and selective in vitro, was evaluated in vivo and revealed both toxicity and inactivity against murine malaria after oral and parenteral administration. The low SI might justify the high toxicity in vivo, and the low bioavailability explains the lack of activity. In fact, quinone methides triterpenoids such as compounds (65 and 66) have been studied for their antitumoral activities $[101,102]$. It was found their quinone methide moiety was responsible for this effect, namely through the induction of apoptotic pathways, be it with mitochondrial targeting, formation of Michael adducts with chaperones, among other interactions [101-104]. Consequently, the in vitro and in vivo lack of specificity becomes logical. These characteristics make the development of these compounds as antimalarials difficult [100, 105].

There are 2 accepted MoA for quinones: the oxidative stress induction and the inhibition of the mitochondria's electron transport and respiratory chain. Quinones are easily reduced into derivatives, which, in turn, can be further reduced [30]. The capability of generating ROS or of a nucleophilic addition reaction on the parasite's proteins depends on the quinone, being more frequent on benzoquinones than anthraquinones or naphthoquinones, possibly because of the decreased electron flow on these structures $[4,99,106]$. Although claimed by many authors, it is unlikely that quinones and derivatives undergo Michael reactions directly with the parasite's DNA, since in physiological conditions, they are known to interact with proteins that possess thiol groups. This is not the case with the parasite's DNA but of other proteins (e.g. chaperones) $[48,99,101,107]$. Therefore, for the more complex and fully conjugated structures, it is accepted that they act in a similar fashion to atovaquone [25]. In the long-term, the blockage of the parasite's mitochondrial electron transport chain by targeting the cytochrome $b c_{1}$ complex interferes with the redox homeostasis and with the pyrimidine biosynthetic pathway, crucial for the parasite's subsistence [3]. In any case, the high antiplasmodial activity of this class of compounds is balanced with the frequently low selectivity and bioavailability, as evidenced thus far. As with lapachol and atovaquone, synthetic derivatives might be designed and optimized; however, the existing resistance to atovaquone invokes the question about whether there is a necessity for new compounds from this chemical class that will perform through the same MoA $[3,15,84]$.

\section{Xanthones}

Xanthones are dibenzo-c-pyrone compounds formed by cyclization of a benzophenone $[50,108]$. The great interest in these compounds is comparable to quinones because of their high in vitro parasiticidal activity and the facility of synthesis $[50,108]$. The antiplasmodial activity of these compounds against both sensitive and resistant strains, in a similar fashion to the quinoline class of antimalarials, has made it one of the most studied phenolic phytochemical classes [108]. In spite of this, only 8 compounds corresponded to the criteria and are presented in $>$ Table 6 and Fig. 6. 


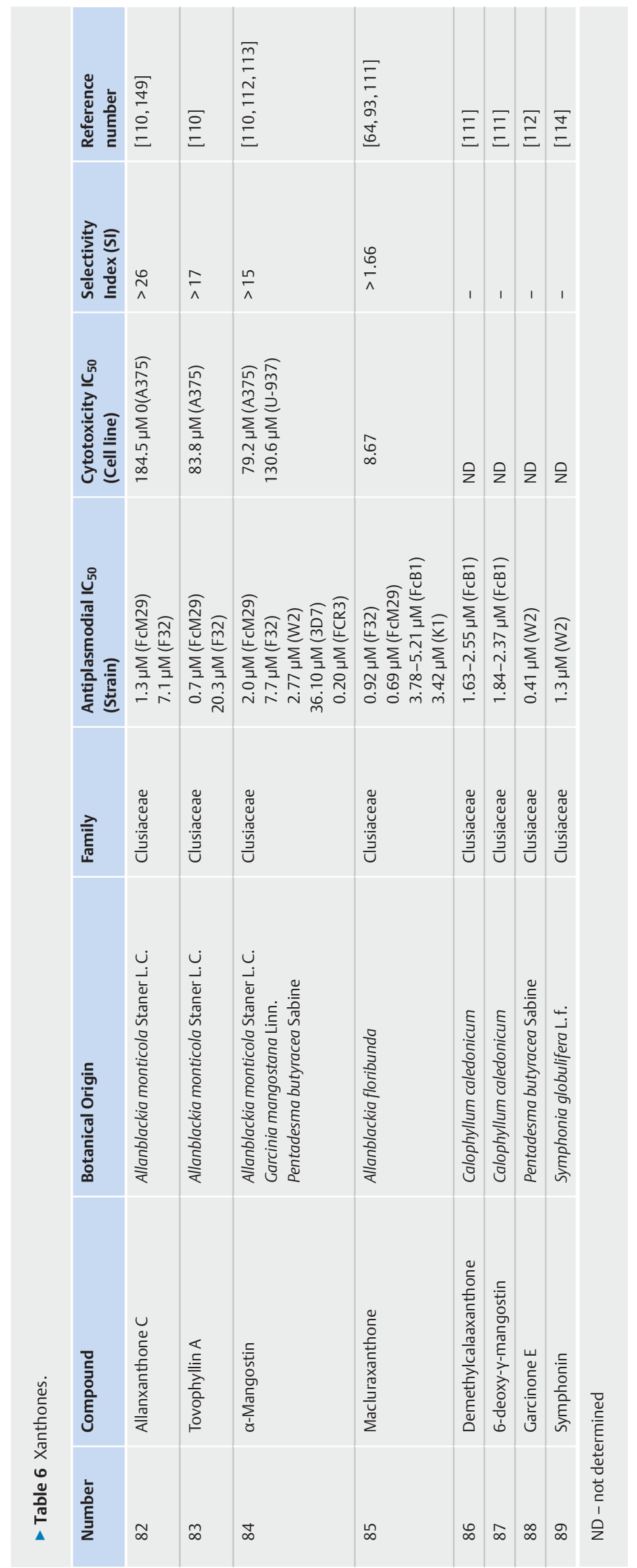


<smiles>CC(C)=CCc1c(O)cc2oc3c(c(=O)c2c1O)C(CC=C(C)C)(CC=C(C)C)C(=O)C(O)=C3</smiles><smiles>COc1c(O)cc2oc3cc(O)c(CC=C(C)C)c(O)c3c(=O)c2c1CC=C(C)C</smiles>

84<smiles>CC=C(C)C</smiles><smiles>CCc1c(O)c(O)c(CC=C(C)C)c2oc3cc(O)c(CC=C(C)C)c(O)c3c(=O)c12</smiles><smiles>CC(C)=CCc1c(O)cc2oc3c(CC=C(C)C)c(O)c4c(c3c(=O)c2c1O)C=CC(C)(C)O4</smiles><smiles>C=CC(C)(C)c1c2c(c(O)c3c(=O)c4ccc(O)c(O)c4oc13)C=CC(C)(C)O2</smiles>

85<smiles>CC(C)=CCc1c(O)cc2oc3ccc(O)c(CC=C(C)C)c3c(=O)c2c1O</smiles>

87<smiles>COc1cc2c(=O)c3c(O)c(CC=C(C)C)c4c(c3oc2c(O)c1OC)C=CC(C)(C)O4</smiles>

89

- Fig. 6 Molecular structures of xanthones. 
There are 2 characteristics that stand out across the compounds presented: the prenylation and cyclization of the xanthone structure. $\alpha$-Mangostin (84) is one of the most studied xanthones because of its several activities: antimicrobial, antioxidant, anti-inflammatory, antiviral, and antimalarial [109]. Compounds (82, 87 , and 88 ) are all structurally related to $\alpha$-mangostin (84), as - Fig. 6 suggests. These compounds, besides the xanthone skeleton, have in common 1 or 2 prenyl groups at C-1 and C-7 and a hydroxyl at C-6. These characteristics appear to be important for activity [109-112]. Although this group has been tested on different strains and assays, it is possible to point out that compound (88) is the most active of the 4 , with an $\mathrm{IC}_{50}$ of $0.41 \mu \mathrm{M}$ on the W2 strain, while (84) retains activity mostly against the chloroquine-resistant strains [113]. In vivo studies with (84) demonstrated a low antimalarial activity when orally administered at $100 \mathrm{mg} /$ $\mathrm{kg} /$ day in a 7-day test, when compared to intraperitoneal administration of the same dose twice per day, from $27 \%$ to $81 \%$ chemo suppression, respectively [113]. This might be due to low bioavailability that hinders absorption at the digestive level [113]. In spite of positive hemolysis results (at $69.7 \mu \mathrm{M}$ ), the SI was found to be high enough, as demonstrated in vivo by the reduction of malariarelated symptoms and overall absence of toxicity at all levels tested (hepatic, renal, and histological) [113].

Compound (88) structurally differs from the others with an additional prenyl at C-4, which might indicate that lipophilia might play an important role on these compounds' MoA. Further studies to evaluate the structure-activity relation of these compounds revealed that the prenyl group at C -1 and the hydroxyl at C -3 are fundamental characteristics for antiplasmodial activity [50]. In this regard, it would be interesting to study (82 and 88) on different strains in order to ascertain if the double prenyl group at C-1 or the carbonyl at C-2 are important toward a certain type of strain. The fact compounds (84 and 87 ) were isolated from traditionally used plants further demonstrates their activity [112].

Compounds $(83,86$, and 89 ) have incurred both prenylations and cyclization. Considering the aforementioned characteristics for active xanthones, compound (83), apparently the most active of the trio, fits the criteria and demonstrates that a cyclization at C-1-C-2 does not interfere with activity [110].

Finally, compound (85) has a 12-(2-methylbut-3-en-2-yl) group and a dihydropyrano ring. This structure proves to be preferential toward activity in comparison to other isolated structures in the same study, particularly to the F32 and FcM29 strains [111]. Likewise, with the other xanthones thus far, it stands out in the difference in activity between chloroquine-resistant and -sensitive strains. Most compounds presented have higher activities on resistant strains rather than the chloroquine-sensitive ones. This is odd, considering that the MoA of xanthones is defined as a complexation with heme, preventing the detoxification of the digestion of hemoglobin that, this way, kills the parasite (see $>$ Fig. 1) $[25,50,108,114]$. This MoA is similar to the quinoline class of antimalarials. Resistance to chloroquine, in particular, originates in the modification of a transporter in a digestive vacuole of the parasite, consequently altering its accumulation and preventing its activity $[115,116]$. The fact that xanthones are active against chloroquine-resistant strains evidences a bypass through this mechanism of resistance, representing a lead to discover the structural requirements to this ability. However, none of the xanthones have a great SI, which might indicate a lack of structural selectivity that impeaches their utilization as antimalarials.

\section{Lignans}

Lignans are dimeric phenylpropanoids connected by $\mathrm{C}-\mathrm{C}$ bonds between the $\beta$-carbon of the propanoid chain [50]. When the C-C bond is established differently, the compounds are termed neolignans. These compounds, shown in > Table 7 and Fig. 7 , are known for their toxicity and general activity, including antiprotozoal [117].

Compounds (90 and 91) are considered neolignans because of their unusual linkage between monomeric units. Compound (90) is active equally against resistant and sensitive strains. In a study, 3 compounds, including (90), were isolated and tested. Compound (90) was the most active of the 3 , with an average $I C_{50}$ of $0.9 \mu \mathrm{M}$ between sensitive and resistant strains, and, structurally, that demonstrated that the double bond on C-7'-C-8' was preferential for activity, possibly due to the easiness of the conjugated double bond to generate ROS [118]. Compound (91) has an unconventional molecular structure, with a peroxide ester that might function similarly to the endoperoxide bridge of the artemisinin class of antimalarials [118]. Its activity, however, is not comparable to that class of drugs, with an $\mathrm{IC}_{50}$ of over $1.4 \mu \mathrm{M}$, which points to a different MoA [118]. Neither compound has good SI, making them non-ideal for further studies.

Compounds (92-95) were all isolated from the same Brazilian plant [117]. The in vivo activity of the hexane extract, with a parasite reduction of $67 \%$ and $48 \%$, for the root and leaves extracts, respectively, prompted the isolation and in vitro testing of these compounds [117]. All 4 lignans proved to be very active against the chloroquine-resistant isolate $(\mathrm{BHz} 26 / 86)$, with $\mathrm{IC}_{50}$ between 0.20 and $0.63 \mu \mathrm{M}$ [117]. It is thus possible to infer the structural requirements for activity: a trans orientation in the B-ring and a veratryl A-ring, with no particular difference between an O-methyl or a methoxy at C-3' and C-4'. Contrarily to the previous lignans and to the general idea of toxicity, these 4 compounds were found non-toxic on Hep G2 A16 hepatic cells [117]. This could mean that traditional lignans present advantages both activity- and toxicitywise. The MoA of these natural compounds is currently unknown, although, as discussed previously, it might be linked to the generation of ROS.

\section{Other Derivatives}

Other subgroups of phenolic compounds with relevant antiplasmodial activity are displayed in $>$ Table $\mathbf{8}$ and Fig. $\mathbf{8}$. Their individuality demonstrates, coupled with the compounds discussed thus far, the variability of phenolic structures with antiplasmodial activity that may prove to be important for the discovery of new antimalarials.

Licochalcone A (96) is a chalcone, an aromatic ketone, isolated from the Chinese licorice roots [119]. It is not frequent to find chalcones in plants, as they are precursors of flavonoids and therefore are often transformed into these compounds and derivatives $[26,27,50,120]$. Compound (96) was the first chalcone to 


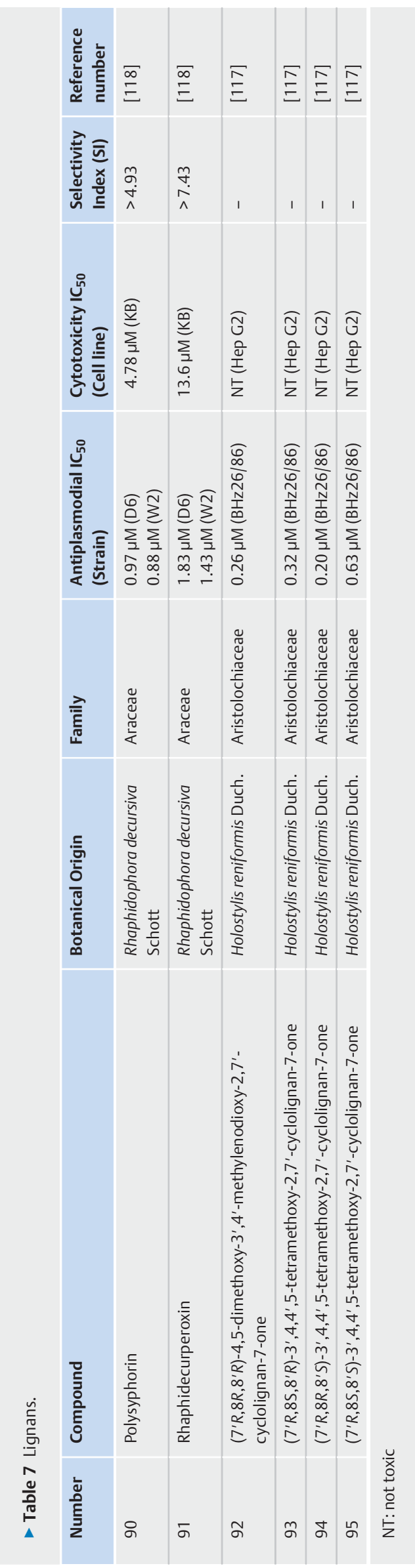

reveal the potential of the phytochemical class as antimalarials, besides as antibacterial, antiviral, and antileishmanials $[26,121]$. Its activity was demonstrated in vitro against all erythrocytic stages of the parasite, proving the effectiveness in important metabolic pathways throughout the parasite's life cycle [122]. In vivo, in $P$. yoelii YM-infected mice, the administration of $15 \mathrm{mg} / \mathrm{kg}$ 4 times daily intraperitoneally, for a total of $60 \mathrm{mg} / \mathrm{kg}$, for 3 consecutive days, accounted for parasite clearance $(93 \%)$ without toxicity [122]. In the same test, (96) was administered orally at doses of 450,150 , and $50 \mathrm{mg} / \mathrm{kg} /$ day, and it demonstrated to nearly clear the parasitemia at all doses, with no mortality by the end of the study (21 days) [122]. On the one hand, the bioavailability of (96) allows for an ideal oral antimalarial; on the other hand, it is unclear whether the administration several times a day and for a long period of time, at least over 3 days, would be practical. This compound's MoA has been thoroughly studied: it is thought the major mechanism is the inhibition of the mitochondria's cytochrome bc1 complex, similarly to atovaquone [120]. However, chalcones have other MoA, different from the activity reported for compound (96): hematin degradation inhibition, preventing detoxification; hemoglobinase inhibition, preventing digestion of hemoglobin; and new permeation pathways inhibition, leading to the parasite's death (see $>$ Fig. 1) $[50,120]$. Structural studies revealed that the properties of the B-ring proved important for antiplasmodial activity, as did the number of methoxy substitutions and the hindrance caused by them, thus impeaching the connection to the enzymes responsible for the previous steps $[121,123]$. Overall, the potential of compound (96) and the facility of creating synthetic derivatives has made chalcones a potential group for derivation of innovative antimalarial structures [121].

Compound (97) is the only lactone to fill the pre-set requirements. It is a valerolactone, a 5-carbon ester cycle, isolated from Phragmanthera capitate, an African parasitic plant used to treat fever and parasitic diseases [124]. In the same study where it was isolated, a second lactone was also identified with a single structural difference: the phenolic ring substitution of a hydroxyl, instead of a galloyl group. Although compound (97) does not have a promising antiplasmodial activity of its own, it is interesting to note that the difference between the 2 compounds is over 100fold [124]. This demonstrates undoubtably, as mentioned previously, the advantage activity-wise that the galloyl moiety awards, compared to a single hydroxyl group. It is possible compound (97) acts in a similar way to phenols.

Compounds (98 and 99) are hexahydrodibenzopyrans with a monoterpene moiety isolated from an Amazonian plant [125]. The structural difference between the 2 is a cyclization at C -1 ' with an oxygen in a $1^{\prime}, 2^{\prime}$-dihydrofuran. This divergence is enough to accentuate the antiplasmodial activity of (99) over 2 -fold, for the chloroquine-resistant strain, and over 5 -fold, for the-sensitive strain, in relation to compound (98) [125]. It is possible the dihydrofuran ring might contribute to the conformational rigidity of the compound or its electron flow, augmenting its potential antiprotozoal activity. In any case, without the SI, general toxicity cannot be overlooked, making these compounds unlikely future antimalarials. 


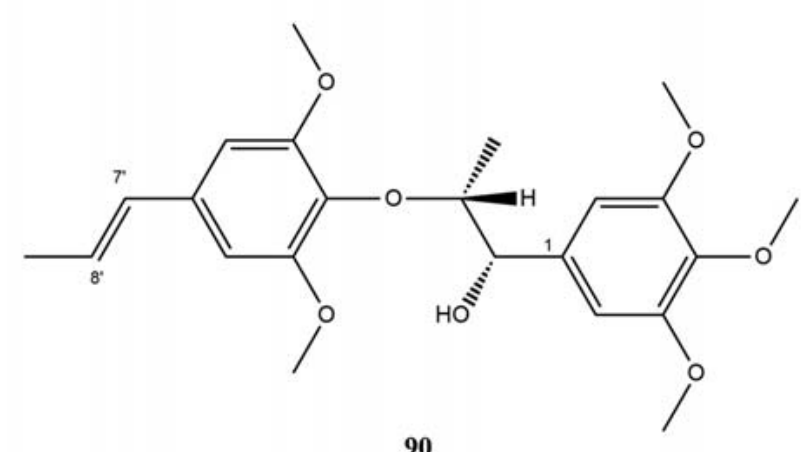

90<smiles>[R20]Oc1ccc([C@H]2c3cc(OC)c(OC)cc3C(=O)[C@@H](C)[C@@H]2C)cc1OC</smiles>

$92 \mathrm{R}_{1}=\mathrm{R}_{2}=\mathrm{CH}_{2}$

$93 \mathrm{R}_{1}=\mathrm{R}_{2}=\mathrm{CH}_{3}$<smiles>COc1ccc([C@@H]2c3cc(OC)c(OC)cc3C(=O)[C@@H](C)[C@H]2C)cc1OC</smiles>

94<smiles></smiles>
is not directly defined solely by these assays. The ability to better fevers or anemia is highly valued by the patients, who often do not have the capability of reaching out for professional help or to pay for the recommended treatments. Future traditional medicine applications will require effectiveness validation and standardization into improved traditional medicines, as is recognized by the World Health Organization [126]. As a result, although the cost may rise, these might still prove a preferential option to purified or synthesized drugs, with the added advantage that the process could be developed locally, which would improve the accessibility of these medicines $[10,12,126,127]$. In order to verify the safety of consumption and enable future medical applications but also to enlarge the data pool of interesting antiplasmodial compounds, it is important to continue to screen and study traditional medicinal plants.

To target malaria, the 6 most interesting sub-groups of phenolic compounds were condensed and will now be analyzed. For an integral view of the MoA on the parasite, see $\boldsymbol{\nabla}$ Fig. $\mathbf{1}$.

Phenolic acids, phenols, and their derivatives conserve simple phenolic moieties and are, therefore, related to several MoA. They are capable of inhibiting hemoglobin digestion and hemozoin formation, disturbing the redox homeostasis and, possibly, iron chelating $[40,49]$. However broad their reach, no selected compound from this class excels at differentiating themselves as antiplasmodials. In fact, the low bioavailability, rapid metabolization, and non-consistent selectivity and activity toward all types of strains represent important characteristics that prevent interest in this class of compounds $[37,43,47]$. It is noteworthy to mention that in other classes of compounds, the galloyl or gallate moiety substitution has shown to improve the compound's activity, as evidenced throughout this review. Still, these structures show no relevant potential on their own $[33,34]$.

In a similar fashion, no coumarin stands within the selected compounds. Overall, all present a wide-range of concentrations that are unreliable concerning the necessary characteristics of an antimalarial $[22,28]$. The lack of studies regarding their MoA and selectivity also leaves an information void. Further studies would 


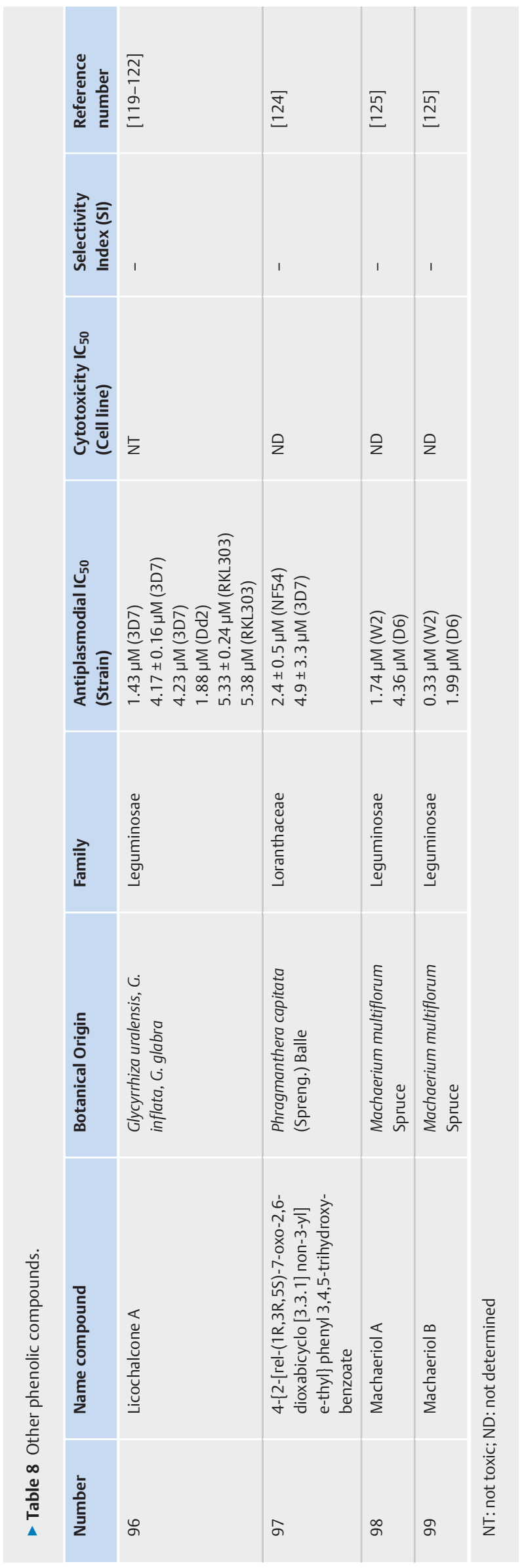

be necessary to confirm the contribution this class could give, especially considering that there are coumarins identified as the active compounds of traditionally used plants $[8,51]$.

The flavonoid phytochemical class is one of the most extensive and varied classes approached in this review. Its structural variation is great, and, as mentioned previously, the criteria of this review allowed the narrowing of the ideal characteristics of the active structures: flavone, biflavone, and biflavanone (see - Fig. 9). Not only are there multiple molecules with considerable structure-activity co-relation, but the known MoA by which they act are multiple $[4,55]$.

Of the 34 flavonoids presented, 3 are of interest: compound $(11,21$, and 37$)$. All are dimeric structures, a biflavone, and biflavanones. They demonstrate a good antiplasmodial activity against both multidrug-resistant and -sensitive strains with a great SI [63, $66,67,128]$. Compound (11) appears to have the ideal structure for FAS inhibition: a planar structure (double bond C-2-C-3) and hydroxy groups at C-5 and C-7 $[63,128]$. Although its B-ring does not possess hydroxy groups, it could be that the other characteristics are enough to represent antiplasmodial activity. Compounds (21 and 37) fall far from these characteristics, possibly justifying its activity through the number and position of the hydroxy groups $[66,67]$. The most active catechins are the ones with a galloyl moiety at C-3, of which compound (50) is the most active of the presented $[55,72]$. Unfortunately, the range of concentrations needed for (50) to act as antiplasmodial could coincide with the therapeutic window of other activities, imposing care in its utilization [72]. In this regard, flavonoids appear safer and more active, and, therefore, more promising to study as antimalarials than catechins.

In the symptomatic phase of malaria, which is understood as the erythrocytic stage of the parasite's life cycle, the parasite has to maintain a relatively sensitive homeostasis. Particularly its redox homeostasis, since not only does its digestion of hemoglobin and the mitochondrial activity originate oxidative stress, but also the host's immune system attacks with ROS $[129,130]$. The host's erythrocyte is also receiving oxidative insults, which means the parasite must maintain both systems' redox homeostasis if it wants to survive $[43,129,130]$. In the fight to prevent lipid peroxidation, inactivation of enzymes and ion channels, protein oxidation and inhibition of mitochondrial respiration, the parasite is equipped with an antioxidant system that includes glutathione proteins and superoxide dismutase [43]. When antimalarials are able to saturate this system and disturb the already fragile redox balance, the cascade of oxidative damage ensures the parasite's death [130]. Flavonoids are recognized powerful antioxidants that, in certain conditions of concentration and the presence of metal ions, as occurs within the erythrocytic stage of the parasite, act as pro-oxidants. This disturbs this vital balance and leads to the parasite's death. Particularly the B-ring of flavonoids may be converted to a phenoxy radical anion (as semiquinones) under extreme stress $[4,45]$.

Flavonoids, and particularly green tea's catechins, remain the main group of phenolic compounds with evidenced antiFAS activity $[55,63,72]$. Both mammal cells and the Plasmodium sp. use the FAS system to perform the elongation cycle of fatty acids. The structural differences between type I (eukaryote) and type II 
<smiles>C=CC(C)(C)c1cc(/C=C/C(=O)c2ccc(O)cc2)c(OC)cc1O</smiles>

96<smiles>O=C1C[C@@H]2O[C@@H](C[C@@H](CCc3ccc(OC(=O)c4cc(O)c(O)c(O)c4)cc3)[C@H]2O)O1</smiles>

97<smiles>C[C@H]1CC[C@@]2(C)[C@@H](C1)c1c(O)cc(/C=C/c3ccccc3)cc1OC2(C)C</smiles>

98<smiles>C[C@H]1CC[C@@]2(C)[C@@H](C1)c1c(O)cc(-c3cc4ccccc4o3)cc1OC2(C)C</smiles>

99

Fig. 8 Molecular structures of other phenolic derivatives.

(among others, protozoa) allow this essential system to be targeted by antimalarials [72]. Both the FAS system and a part of the protein synthesis occur in the apicoplast, where flavonoids interact with the pertinent enzymes and inhibit this pathway [55, 72].

An ingenious MoA that was ultimately never implemented is iron chelating. Iron is essential for protozoa, among other infectious species, to thrive and is the main concern when invading a host [16]. Iron chelators induce death by iron-starvation, possibly preventing the use of iron on the mitochondria's respiratory chain or for DNA synthesis [16]. Overall, flavonoids represent an alternative to conventional iron chelators that have unreasonable requirements of therapy time and dangerous secondary effects [78]. Flavonoids have the property to starve the parasite of iron, while not being as aggressive to the host as the known synthetic iron-chelators $[54,75]$.

Additionally, and finally, an innovative, although relatively unexplored, antiplasmodial target is the inhibition of new permeation pathways. After $6 \mathrm{~h}$ post-invasion, the parasite alters the constitution of the host's cell membrane with its own proteins in order to make it permeable to more compounds [131]. Anions, but not cations, and small compounds, like monosaccharides, but not disaccharides, become available to the parasite $[120,131,132]$. The homeostasis of the whole structure is again threatened, since the osmotic status and erythrocyte membrane potential might be altered. Flavonoids have the capability of inhibiting these perme- ations' pathways, altering the metabolism of the parasite, leading to its death [120]. Hemolysis and immune recognition might be part of the killing process [132].

The versatility and multiple approach capacity make flavonoids the most interesting class in this paper. They are highly active against various strains of $P$. falciparum, with a $\mathrm{SI}$ of, overall, at least higher than 4 . This represents their safety, also expressed by the exclusive and varied pathways through which they target the parasite alone. These compounds have prolonged half-lives and have an history of dietary importance, making them at least apparently safe for children and pregnant women $[4,63,71]$. Their solubility is enough to quench the long-sought requirement that most identified antiplasmodials cannot meet, not to mention its wide distribution, which should make these compounds lowcostly. Their presence in traditional plants used against malaria in endemic places not only validates their use to a certain extent but evidences their viability as chosen promising compounds $[4,63$, 71]. Lastly, although it depends on the chosen flavonoid, there is no reason to believe the compound could not be used in ACTs; proven activity tests are made to distinguish the ACT's MoA from the flavonoid's.

The quinones and their derivatives presented and discussed have various structures; the most promising appear to be anthraquinones and anthrones. The most interesting anthraquinone is compound (55), a knipholone derivative with a glucopyranoside that awards it an additional edge in both activity and selectivity 
<smiles>CC(C)=CCc1cc(CC=C(C)C)c2oc(-c3ccc(O)c(O)c3)c(CC=C(C)C)c(=O)c2c1</smiles>

Flavone

$\mathrm{R}=\mathrm{H}, \mathrm{Me}$ or $\mathrm{Ac}$

* or cyclization<smiles>[R]Oc1ccc([C@H]2Oc3cc(O)ccc3C(=O)[C@H]2[C@H]2C(=O)c3ccc(O)cc3O[C@H]2c2cccc([R2])c2)cc1</smiles>

Biflavanone

$$
\mathrm{R}=\mathrm{H} \text { or } \mathrm{CH}_{3}
$$<smiles></smiles><smiles>[R]Oc1ccc(-c2cc(=O)c3c(O)cc([R])c([X])c3o2)cc1</smiles><smiles>[R20]c1cc(O)c(C(C)=O)c(O)c1-c1ccc(O)c2c1C(=O)c1cccc(O)c1C2=O</smiles>

Anthraquinone

$\mathrm{R}_{1}=\mathrm{H}$ or $\mathrm{CH}_{3}$

$\mathrm{R}_{2}=\mathrm{CH}_{3}$ or glucopyranoside<smiles>[R20]c1cc(O)c2c(O)c3c(cc2c1)CC([R6])(C)C(CC=C(C)C)C3=O</smiles>

Anthrone

$\mathrm{R}_{1}=\mathrm{H}$ or $\mathrm{Ac}$

$\mathrm{R}_{2}=$ Prenyl or Geranyl

- Fig. 9 Projected ideal molecular structures per phytochemical class. Based on the discussed information of relation structure-antiplasmodial activity.

[91]. Likewise, compound (75) is the most interesting anthrone, a vismione with a geranyl group at C-7 and an acetyl group at C-2, attaining the same advantage [94]. It is noteworthy that, overall, the presented quinones all have high antiplasmodial potentials. It is their SI that represents a liability in transforming these compounds into antimalarials. Both compounds (55 and 75) may present structure-activity starting points toward a solution to this problem. - Fig. 9 shows the ideal structures to be considered for further studies. Activity-wise, quinone structures can be oxidized to semiquinones that function as Michael acceptors in nucleophilic additions that establish covalent bonds with proteins, significantly damaging the parasite $[49,99]$. However, this might not happen exclusively in the parasite, which is why the $\mathrm{SI}$ is not always optimal. Naphthoquinones have high affinities to the cyto- 
- Table 9 The antioxidant activity of some phenolic compounds.

\begin{tabular}{|c|c|c|c|c|}
\hline Compound & Name & Type of compound & Antioxidant Activity & Reference \\
\hline 3 & Ellagic acid & Phenolic acid & $\begin{array}{l}1.1 \mu \mathrm{M}^{1} \\
8.24 \mu \mathrm{M}^{2} \\
35.71 \pm 2.5 \mu \mathrm{M}^{3} \\
13.63 \mu \mathrm{M}^{4}\end{array}$ & {$[35,39]$} \\
\hline 6 & 4-Nerolidylcatechol & Catechol & $75 \%^{2}$ & [49] \\
\hline 49 & Epicatechin & Catechins & $1.41 \mu \mathrm{M}^{2}$ & [71] \\
\hline 50 & Catechin-gallate & Catechins & $1.27 \mu \mathrm{M}^{2}$ & [71] \\
\hline 51 & Epicatechin-gallate & Catechins & $1.18 \mu \mathrm{M}^{2}$ & [71] \\
\hline 79 & $\begin{array}{l}2^{\prime} E, 6^{\prime} E \text { 2-farnesyl } \\
\text { hydroquinone }\end{array}$ & Quinone & $\begin{array}{r}10.8 \pm 0.09 \mu \mathrm{M}^{2} \\
8.4 \pm 0.11 \mu M^{3 *}\end{array}$ & [80] \\
\hline 89 & Symphonin & Xanthone & $23 \% \pm 0.4^{2}$ & [114] \\
\hline 96 & Licochalcone A & Chalcone & Equal to Vitamin $E^{5}$ & {$[150]$} \\
\hline \multicolumn{5}{|c|}{ 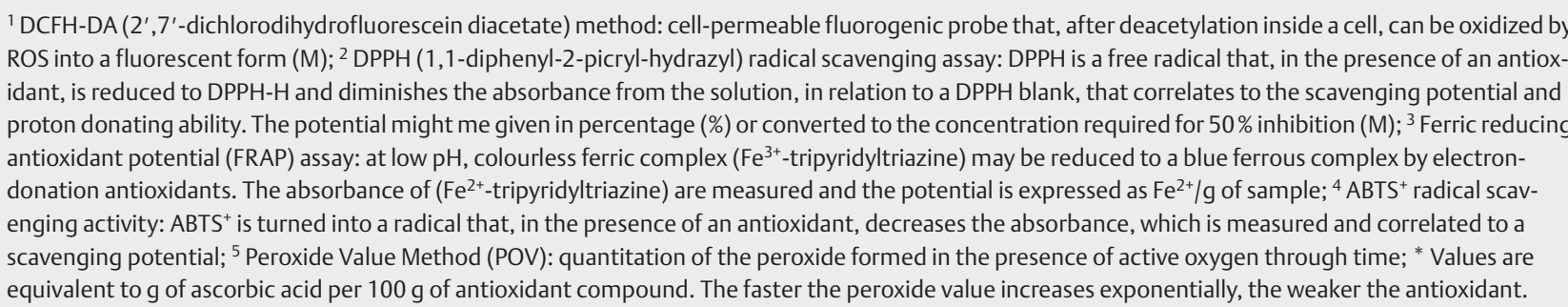 } \\
\hline
\end{tabular}

chrome $b c_{1}$ complex within the parasite's mitochondria respiratory chain, a specific parasitic structure, justifying the SI of atovaquone and similar acting compounds [84]. However, as formerly discussed, parasites with resistance to atovaquone exist and have limited its use. This represents an obstacle in the interest of developing this class further, unless these new phenolic compounds could prove to bypass this resistance.

Xanthones, as discussed previously, appear to be a particularly interesting class of antiplasmodials. They display somewhat a preference in activity toward chloroquine or multidrug-resistant strains. How this happens may be unknown, but it certainly demonstrates an advantage against the resistant parasite. It is noteworthy that all the isolated xanthones originated in the same family, Clusiaceae, broadly distributed in tropical regions, similarly to malaria [93]. The most impactful characteristic toward activity and selectivity seems to be the prenylation at key carbons with 2-methylpent-2-ene groups. A substitution with another group, as in compound (85), demonstrates great activity, but low selectivity, indicative of general toxicity $[64,93,111]$. As mentioned in the related section, not only do hydroxyl groups at positions C-3, C-6, and C-8 improve xanthones' activity but also prenylations at C-1, C-4, and C-7 do as well (see - Fig. 9). A good example of a promising xanthone would be compound (83), with a 20 -fold preferential activity toward the chloroquine-resistant strain and a good SI [110]. Its cyclization at C-1-C-2 could be the responsible factor, acting in a similar fashion, or better, to the carbon chain at $\mathrm{C}-1$. It is possible the improved lipophilia of the carbon chains facilitates the entrance and accumulation of these compounds inside the digestive vacuole, easing their antiplasmodial activity as inhibitors of the hemozoin formation $[109,133]$. Also, because the electrostatic potential of xanthones is directly related to their antiplasmodial activity, an additional ring may complement an electrostatic profile that allows the interactions with hematin, preventing its transformation [108].

Lignans, according to the present findings, are compounds with high antiplasmodial potential and varied SI. Compound (94) is a very interesting lignan with an outstanding activity against a chloroquine-resistant strain and no toxicity against Hep G2 A16 cells [117]. However, it is uncertain if lignans could be an innovative antimalarial structure, since most screened lignans are recognized for their general toxicity, unwarranted in malaria's case [117]. Additionally, their MoA is uncertain and would require further studies to ascertain the interest in this phytochemical class.

It is pertinent to discuss, considering the topic of phenolic compounds, their antioxidant properties in the context of the malaria disease. Phenolic compounds are considered powerful antioxidants with the capacity to turn into powerful oxidants when certain conditions are met, for example, their concentration. The easier the oxidation of the phenolic compound (i.e., the highest the phenoxyl radical/phenol redox ratio), the higher the antiplasmodial activity [4]. Studies have shown that the higher the oxidation potential of phenols, the higher the selectivity toward the parasite [106], which means phenolic compounds could be selected for their oxidation potential in order to improve their selectivity and, consequently, antiplasmodial activity. However, considering that this potential depends on certain conditions, if the antioxidant potential overthrows the oxidant, the antiplasmodial activity might become compromised, begging the question if this type of activity is reliable in the context of malaria [130]. > Table $\mathbf{9}$ gives an overview on the antioxidant potential of some of the discussed antiplasmodial phenolic compounds. Most compounds in this table are proton donors, as represented by their high anti- 
oxidant values. Compounds (79) is an exception, an electron donor that can act as a nucleophile in Michael reactions [80]. Compound (89) is also a noteworthy exception, the weakest antioxidant of its study but also the most active antiplasmodial, evidencing how xanthones have other MoA [114]. If antioxidants are ever to be included in antimalarial therapy, all factors need to be taken into consideration.

The path that connects the discovery to the development of a new antimalarial is both expensive and time-consuming. A group of accepted criteria exists to help distinguish, as a pre-set, if a compound is promising enough to go on this journey. First, the compound should be a potent antiplasmodial against both resistant and sensitive strains of $P$. falciparum in vitro. This presupposes that the compound targets an essential component to the parasite's survival, an unavoidable route or molecule $[12,18]$. Second, the compound must be selectively toxic to the parasite (i.e., it must use a unique target, divergent from the host) $[12,18]$. This is represented by a high SI. Some authors argue above 4, others above 1000, while accepting that the SI depends on the strains and types of cells tested and it is only an indicative figure [12, 18]. Third, the ability to eradicate murine malaria in in vivo models without any signs of toxicity has been highly suggestive of a promising compound $[12,18]$. Fourth, because the ideal antimalarial is perceived as oral, it is advisable to select the compound with its bioavailability in mind $[12,18]$. Other criteria might also be considered, such as a long half-life, no recrudescence, active on gametocytes and hypnozoites, no adverse effects, appropriate for pregnant women and children, inexpensive, a therapy no longer than 3 days, and optimally a compound that could be included in ACTs. These are a set of complicated, at times impossible, guidelines to follow for 1 single compound, which makes the development of antimalarials harder than it would appear $[3,5,134$, 135].

In order to obtain information to be able to distinguish promising from not-promising compounds, standard in vitro and in vivo assays are developed, but they possess limitations. The in vitro screening tests account only for the erythrocytic stage, responsible for the disease as it is perceived, namely the fevers and its complications. Therefore, the test cannot detect compounds that act in other stages of the Plasmodium sp. life cycle that would be equally important to target [7]. Even with the SI information, the compounds may still affect different human cells and organs, leading to unwanted effects. In spite of the restriction on interpretation of these tests, they remain the major mechanism through which relevant data may be attained ethically. Unfortunately, the cost of the required apparatus and tests prevents most studies of plants from having a complete profile. In order to define whether a compound could be a promising antimalarial, it is necessary to have a minimum battery of tests that give basic information, such as activity and toxicity, to indicate if in vivo tests, for example, would be worth doing.

In this context, it is important to discuss the emergence of artefacts during assays. It has been discussed that some classes of compounds may appear to be active in various screening tests, only to be discarded when, upon further studies, it is discovered that their activity is not specific [136]. These compounds-called Pan Assay INterference compoundS (PAINS)-are, in fact, reactive chemicals and not selective promising drugs (i.e., they interact generally with multiple proteins or enzymes, sometimes interfering inclusively with the reading of the test) $[136,137]$. This represents a problem in drug discovery, since active components should be selective and discriminant in what structures they interact with. Since most drugs derive from natural compounds, it is only expected that some PAINS classes have structures that appear in nature, as in the case of quinones and catechols [136138]. In both cases, the issue is in their propensity to establish redox reactions, chelate metals, and become nucleophiles that interfere with multiple targets in a cell [137-139]. As discussed previously, these classes have uncertain MoA on the malaria parasite, thus their activity might be justified with these general processes. Tests with curcumin (5), epigallocatechin gallate (47), and quinones have revealed multiple ways in which they interfere with cells, such as connecting easily to proteins through thiol addition, chaperone inactivation, and alteration of intramembrane protein function through partition into the (eukaryote) cell membrane $[99,107,140]$. In the antimalarial discovery context, however, this issue becomes particular. The Plasmodium parasite is intracellular, which means all antimalarials must enter and, to a certain degree, interact with the host cell, the red blood cell. In vitro tests, thus, include both cell systems. Although results are usually revealed through a method that correlates specifically to the parasite, it is undoubtably important to also perform other tests, lysis tests for example, to rule out direct toxicity to the red blood cells. Once more, the selectivity tests gain importance, allowing for the comparison of $\mathrm{IC}_{50}$ on normal cells, which reveals the general toxicity compounds might have. This is the case with compounds (6 and 78 ), a catechol and a quinone respectively, that reveal good activity but also low SI, indicative precisely of no selectivity and, thus, no future applications in this respect. Lastly, it is important to note that, although researchers should be conscious that PAINS exist and might adulterate results, the presence of the molecular structure should not be enough to abandon all interest in a compound $[136,139,141]$. As mentioned previously, atovaquone is a synthetic derivative from lapachol, a quinone, with a described MoA and selective toward the Plasmodium sp., that is currently used in the drug Malarone. This demonstrates how the presence of the quinone moiety was successfully optimized to an approved drug and, likewise, other compounds might follow. In the same order of ideas, ellagic acid (3), exhibiting a catechol moiety, presents high in vitro activity on multiple strains, high SI, and also high in vivo activity in a $P$. vinckei petteri model, which is not coherent with a nonspecific mode of action [37]. Hence, it represents a good example of how future optimization could lead to important findings.

Concerning phenolic compounds, flavonoids and maybe xanthones prove to be the most promising classes. Xanthones are interesting for their capability of bypassing the chloroquine resistance mechanisms, which per se might help to work around this issue. Whether it is its lipophilicity, electronic distribution, or skeleton conformity, and if the structure could be applied to the quinoline antimalarial class would be interesting subjects to explore.

As a side note, attention should be given to the contradiction between the requirement of oral absorption and the evidence that increased lipophilia is a major factor toward antiplasmodial 
activity. Thus far, for most phenolic classes, lipophilia successfully improved the oxidant activity, the entry in the parasite and in its digestive vacuole, while also facilitating the compound's accumulation in the parasite's structures. Upon observing - Fig. 9, it becomes clear most ideal structures include additional rings or hydrocarbon chains, which in turn diminishes the hydrophilia. This presents the importance of maintaining these characteristics in favor of greater antimalarial activities, and, in turn, considering other strategies to develop new drugs, (e.g., different administration routes, different pharmaceutical formulations, or a pro-drug, such as artemisinin, which transforms in dihydroartemisinin, the metabolite that exerts antimalarial effect) [142].

The emergence of future antimalarials might be linked to the study of natural compounds, such as phenolic compounds. These compounds present novel mechanisms to kill the malarial parasite and even possible molecular keys to fight established resistances. However, a long way still lays ahead to take full advantage of these benefits. Unfortunately, some phytochemical classes remain undescribed or understudied regarding their selectivity and MoA, leaving an incomplete profile to work with. Such is the case of coumarins and lignans, as evidenced in this paper. Furthermore, although the 3 most interesting classes- flavonoids, quinones, and xanthones-have available information on them, allowing inclusively the eligibility of interesting compounds from these groups (compounds $11,21,37,55,75$, and 83 ), it is evident that the incomplete data on some compounds may shift the understanding of which ones are the most pertinent to pursue studies. It is essential to have a complete set of data, both the antiplasmodial activity, ideally on multiple strains, and the SI, to be able to discuss compounds as closely as possible. Additionally, for the chosen compounds, in vivo testing remains essential to confirm their potential and should be performed, as part of a complete profile, whenever previous factors support them. Finally, the present review allowed, for the most interesting phytochemical compounds, to preview an ideal molecular structure in order to optimize the antiplasmodial activity. It would be important to synthetize these compounds, test them, and assess further their structure-activity relation. Overall, this review demonstrates the variety of possible future phenolic antimalarials and the potential that natural compounds hold in the fight against malaria.

\section{Acknowledgements}

This work was supported by the Belgian National Fund for Scientific Research (FNRS, grant PDR T.0092.20). The authors would like to thank J. Duarte for his technical support.

Conflict of Interest

The authors declare that they have no conflict of interest.

References

[1] World Health Organization. World Malaria Report 2019. Geneva: World Health Organization; 2019

[2] Pan WH, Xu XY, Shi N, Tsang S, Zhang HJ. Antimalarial activity of plant metabolites. Int J Mol Sci 2018; 19: 1382
[3] Fernández-Álvaro E, Hong WD, Nixon GL, O’Neill PM, Calderón F. Antimalarial chemotherapy: natural product inspired development of preclinical and clinical candidates with diverse mechanisms of action. J Med Chem 2016; 59: 5587-5603

[4] Rudrapal M, Chetia D. Plant flavonoids as potential source of future antimalarial leads. Syst Rev Pharm 2016; 8: 13-18

[5] Cowman AF, Healer J, Marapana D, Marsh K. Malaria: biology and disease. Cell 2016; 167: 610-624

[6] Hostettmann K, Marston A, Ndjoko K, Wolfender JL. The potential of African plants as a source of drugs. Curr Org Chem 2000; 4: 973-1010

[7] Willcox ML, Cosentino M], Pink R, Bodeker G, Wayling S. Natural products for the treatment of tropical diseases. Trends Parasitol 2001; 17: 58-60

[8] Cebrián-Torrejón G, Spelman K, Leblanc K, Muñoz-Durango K, Gutiérrez ST, Ferreira ME, de Arias AR, Figadère B, Maciuk AFA, Grellier P, Cech NB, Poupon E. The antiplasmodium effects of a traditional South American remedy: zanthoxylum chiloperone var. angustifolium against chloroquine resistant and chloroquine sensitive strains of Plasmodium falciparum. Brazilian J Pharmacogn 2011; 21: 652-661

[9] Tagboto S, Townson S. Antiparasitic Properties of medicinal Plants and other naturally Occurring Products. In: Academic Press. Advances in Parasitology. Volume 50. Amsterdam: Elsevier; 2001: 199-295

[10] Wells TN. Natural products as starting points for future anti-malarial therapies: going back to our roots? Malar J 2011; 10: S3

[11] Wright CW. Plant derived antimalarial agents: new leads and challenges. Phytochem Rev 2005; 4: 55-61

[12] Tarkang PA, Appiah-Opong R, Ofori MF, Ayong LS, Nyarko AK. Application of multi-target phytotherapeutic concept in malaria drug discovery: a systems biology approach in biomarker identification. Biomark Res 2016; 4: 25

[13] Cai S, Risinger AL, Nair S, Peng J, Anderson TJC, Du L, Powell DR, Mooberry SL, Cichewicz RH. Identification of compounds with efficacy against malaria parasites from common North American plants. J Nat Prod 2016; 79: 490-498

[14] Saxena S, Pant N, Jain DC, Bhakuni RS. Antimalarial agents from plant sources. Curr Sci 2003; 85: 1314-1329

[15] World Health Organization. Guidelines for the Treatment of Malaria. 3rd ed. Geneva: World Health Organization; 2015

[16] Weinberg ED, Moon J. Malaria and iron: history and review. Drug Metab Rev 2009; 41: 644-662

[17] World Health Organization. World Malaria Report 2018. Geneva: World Health Organization; 2018

[18] Wright CW. Recent developments in research on terrestrial plants used for the treatment of malaria. Nat Prod Rep 2010; 27: 961-968

[19] Caniato R, Puricelli L. Review: natural antimalarial agents (1995-2001). CRC Crit Rev Plant Sci 2003; 22: 79-105

[20] Krettli AU, Andrade-Neto VF, Brandão MDGL, Ferrari WMS. The search for new antimalarial drugs from plants used to treat fever and malaria or plants randomly selected: a review. Mem Inst Oswaldo Cruz 2001; 96: $1033-1042$

[21] De Andrade-Neto VF, Pohlit AM, Pinto ACS, Silva ECC, Nogueira KL, Melo MRS, Henrique MC, Amorim RCN, Silva LFR, Costa MRF, Nunomura RCS, Nunomura SM, Alecrim WD, Alecrim MDGC, Chaves FCM, Vieira PPR. In vitro inhibition of Plasmodium falciparum by substances isolated from Amazonian antimalarial plants. Mem Inst Oswaldo Cruz 2007; 102: 359365

[22] Bero ], Frédérich M, Quetin-Leclercq ]. Antimalarial compounds isolated from plants used in traditional medicine. J Pharm Pharmacol 2009; 61: $1401-1433$

[23] Bero ], Quetin-Leclercq]. Natural products published in 2009 from plants traditionally used to treat malaria. Planta Med 2011; 77: 631-640 
[24] Xu Y], Pieters L. Recent developments in antimalarial natural products isolated from medicinal plants. Mini Rev Med Chem 2013; 13: 10561072

[25] Kaur K, Jain M, Kaur T, Jain R. Antimalarials from nature. Bioorganic Med Chem 2009; 17: 3229-3256

[26] Fournet A, Munoz V. Natural products as trypanocidal, antileishmanial and antimalarial drugs. Curr Top Med Chem 2002; 2: 1215-1237

[27] Schwikkard S, van Heerden FR. Antimalarial activity of plant metabolites. Nat Prod Rep 2002; 19: 675-692

[28] Fletcher S, Avery VM. A novel approach for the discovery of chemically diverse anti-malarial compounds targeting the Plasmodium falciparum coenzyme A synthesis pathway. Malar J 2014; 13: 1-17

[29] Bruneton J. Pharmacognosie: Phytochimie, Plantes Médicinales. Fourth Edit. Paris: Lavoisier; 2009

[30] da Cunha AP. Farmacognosia e Fitoquimica. First Edit. Lisboa: Fundação Calouste Gulbenkian; 2005

[31] Zofou D, Tematio EL, Ntie-Kang F, Tene M, Ngemenya MN, Tane P, Titanji VPK. New antimalarial hits from Dacryodes edulis (Burseraceae), Part I: isolation, in vitro activity, in silico "drug-likeness" and pharmacokinetic profiles. PLoS One 2013; 8: 1-9

[32] Horgen FD, Madulid DA, Angerhofer CK, Pezzuto JM, Soejarto DD, Farnsworth NR. Isolation of gallic acid esters as antiplasmodial constituents of Swintonia foxworthyi (Anacardiaceae). Phytomedicine 1997; 4: 353-356

[33] Aldulaimi O, Uche FI, Hameed H, Mbye H, Ullah I, Drijfhout F, Claridge TDW, Horrocks P, Li WW. A characterization of the antimalarial activity of the bark of Cylicodiscus gabunensis Harms. J Ethnopharmacol 2017; 198: 221-225

[34] Verotta L, Dell'Agli M, Giolito A, Guerrini M, Cabalion P, Bosisio E. In vitro antiplasmodial activity of extracts of Tristaniopsis species and identification of the active constituents: ellagic acid and 3,4,5-trimethoxyphenyl(6'-O-galloyl)-O- $\beta$-D-glucopyranoside. J Nat Prod 2001; 64: 603-607

[35] Reddy MK, Gupta SK, Jacob MR, Khan SI, Ferreira D. Antioxidant, antimalarial and antimicrobial activities of tannin-rich fractions, ellagitannins and phenolic acids from Punica granatum L. Planta Med 2007; 73 461-467

[36] Ríos JL, Giner RM, Marín M, Recio MC. A pharmacological update of ellagic acid. Planta Med 2018; 84: 1068-1093

[37] Soh PN, Witkowski B, Olagnier D, Nicolau ML, Garcia-Alvarez MC, Berry $A$, Benoit-Vical $F$. In vitro and in vivo properties of ellagic acid in malaria treatment. Antimicrob Agents Chemother 2009; 53: 1100-1106

[38] Banzouzi JT, Prado R, Menan H, Valentin A, Roumestan C, Mallie M, Pelissier $\mathrm{Y}$, Blache $\mathrm{Y}$. In vitro antiplasmodial activity of extracts of Alchornea cordifolia and identification of an active constituent: ellagic acid. J Ethnopharmacol 2002; 81: 399-401

[39] Ouattara LP, Sanon S, Mahiou-Leddet V, Gansané A, Baghdikian B, Traoré A, Nébié I, Traoré AS, Azas N, Ollivier E, Sirima SB. In vitro antiplasmodial activity of some medicinal plants of Burkina Faso. Parasitol Res 2014; 113: $405-416$

[40] Dell'Agli M, Parapini S, Basilico N, Verotta L, Taramelli D, Berry CC, Bosisio E. In vitro studies on the mechanism of action of two compounds with antiplasmodial activity: Ellagic acid and 3,4,5-trimethoxyphenyl (6'O-galloyl)- $\beta$-D-glucopyranoside. Planta Med 2003; 69: 162-164

[41] Nandakumar DN, Arun V, Vathsala PG, Rangarajan P, Nandakumar DN, Nagaraj VA, Vathsala PG. Curcumin-artemisinin combination therapy for malaria curcumin-artemisinin combination therapy for malaria. Antimicrob Agents Chemother 2006; 50: 1859-1861

[42] Javeri I, Chand N. Curcumin. Amsterdam: Elsevier Inc.; 2016. doi:10.1016/B978-0-12-802147-7.00031-0

[43] Jain K, Sood S, Gowthamarajan K. Modulation of cerebral malaria by curcumin as an adjunctive therapy. Brazilian J Infect Dis 2013; 17: 579-591
[44] Reddy RC, Vatsala PG, Keshamouni VG, Padmanaban G, Rangarajan PN. Curcumin for malaria therapy. Biochem Biophys Res Commun 2005; 326: $472-474$

[45] Cui L, Miao J, Cui L. Cytotoxic effect of curcumin on malaria parasite Plasmodium falciparum: Inhibition of histone acetylation and generation of reactive oxygen species. Antimicrob Agents Chemother 2007; 51: 488 494

[46] Chakrabarti R, Rawat PS, Cooke BM, Coppel RL, Patankar S. Cellular effects of curcumin on Plasmodium falciparum include disruption of microtubules. PLoS One 2013; 8: 1-14

[47] Haddad M, Sauvain M, Deharo E. Curcuma as a parasiticidal agent: a review. Planta Med 2011; 77: 672-678

[48] Priyadarsini KI. Chemical and structural features influencing the biological activity of curcumin. Curr Pharm Des 2013; 19: 2093-2100

[49] Mendanha Da Cunha CR, Mendanha Neto SA, Carlos Da Silva C, Cortez AP, Gomes MDN, Martins Fl, Alonso A, Rezende KR, Menegatti R, De Magalhães MTQ, Valadares MC. 4-Nerolidylcatechol and its synthetic analogues: antioxidant activity and toxicity evaluation. Eur J Med Chem 2013; 62: 371-378

[50] Schmidt T], Khalid SA, Romanha AJ, Alves TM, Biavatti MW, Brun R, Da Costa FB, de Castro SL, Ferreira VF, de Lacerda MV, Lago JH, Leon LL, Lopes NP, das Neves Amorim RC, Niehues M, Ogungbe IV, Pohlit AM, Scotti MT, Setzer WN, de N C Soeiro M, Steindel M, Tempone AG. The potential of secondary metabolites from plants as drugs or leads against protozoan neglected diseases, part II. Curr Med Chem 2012; 19: 2176 2228

[51] Subeki S, Matsuura H, Takahashi K, Yamasaki M, Yamato O, Maede Y, Katakura K, Kobayashi S, Trimurningsih T, Chairul C, Yoshihara T. Antibabesial and anti-plasmodial compounds from Phyllanthus niruri. J Nat Prod 2005; 68: 537-539

[52] Chung IM, Ghimire BK, Kang EY, Moon HI. Antiplasmodial and cytotoxic activity of khellactone derivatives from Angelica purpuraefolia Chung. Phyther Res 2010; 24: 469-471

[53] Yenjai C, Sripontan S, Sriprajun P, Kittakoop P, jintasirikul A, Tanticharoen $\mathrm{M}$, Thebtaranonth Y. Coumarins and carbazoles with antiplasmodial activity from Clausena harmandiana. Planta Med 2000; 66: 277-279

[54] Cherrak SA, Mokhtari-Soulimane N, Berroukeche F, Bensenane B, Cherbonnel A, Merzouk H, Elhabiri M. In vitro antioxidant versus metal ion chelating properties of flavonoids: a structure-activity investigation. PLoS One 2016; 11: 1-21

[55] Tasdemir D, Lack G, Brun R, Rüedi P, Scapozza L, Perozzo R. Inhibition of Plasmodium falciparum fatty acid biosynthesis: evaluation of FabG, FabZ, and Fabl as drug targets for flavonoids. J Med Chem 2006; 49: 33453353

[56] Bringmann G, Ochse M, Zotz G, Peters K, Peters EM, Brun R, Schlauer ]. 6-hydroxyluteolin-7-O-(1- $\alpha$-rhamnoside) from Vriesea sanguinolenta Cogn. and Marchal (Bromeliaceae). Phytochemistry 2000; 53: 965-969

[57] Widyawaruyanti A, Subehan S, Kalauni SK, Awale S, Nindatu M, Zaini NC, Syafruddin D, Asih PBS, Tezuka Y, Kadota S. New prenylated flavones from Artocarpus champeden, and their antimalarial activity in vitro. J Nat Med 2007; 61: 410-413

[58] Wahyuni TS, Ekasari W, Widyawaruyanti A, Hirasawa Y, Morita H, Zain NC. Artopeden A. A new antiplasmodial isoprenylated flavone from Artocarpus champeden. Heterocycles 2009; 79: 1121-1126

[59] Bourjot M, Apel C, Martin MT, Grellier P, Nguyen VH, Guéritte F, Litaudon M. Antiplasmodial, antitrypanosomal, and cytotoxic activities of prenylated flavonoids isolated from the stem bark of artocarpus styracifolius. Planta Med 2010; 76: 1600-1604

[60] Alkandahri MY, Berbudi A, Subarnas A. Active compounds and antimalaria properties of some medicinal plants in Indonesia - a review. Syst Rev Pharm 2018; 9: 64-69 
[61] Auffret G, Labaied M, Frappier F, Rasoanaivo P, Grellier P, Lewin G. Synthesis and antimalarial evaluation of a series of piperazinyl flavones. Bioorganic Med Chem Lett 2007; 17: 959-963

[62] Abdalla MA, Laatsch H. Flavonoids from Sudanese Albizia zygia (Leguminosae, subfamily Mimosoideae), a plant with antimalarial potency. African J Tradit Complement Altern Med 2012; 9: 56-58

[63] Weniger B, Vonthron-Sénécheau C, Kaiser M, Brun R, Anton R. Comparative antiplasmodial, leishmanicidal and antitrypanosomal activities of several biflavonoids. Phytomedicine 2006; 13: 176-180

[64] Azebaze AGB, Teinkela JEM, Nguemfo EL, Valentin A, Dongmo AB, Vardamides JC. Antiplasmodial activity of some phenolic compounds from cameroonians allanblackia. Afr Health Sci 2015; 15: 835-840

[65] Ahmed MS, Galal AM, Ross SA, Ferreira D, ElSohly MA, Ibrahim ARS, Mossa JS, El-Feraly FS. A weakly antimalarial biflavanone from Rhus retinorrhoea. Phytochemistry 2001; 58: 599-602

[66] Konziase B. Protective activity of biflavanones from Garcinia kola against Plasmodium infection. J Ethnopharmacol 2015; 172: 214-218

[67] Ichino C, Kiyohara H, Soonthornchareonnon N, Chuakul W, Ishiyama A, Sekiguchi H, Namatame M, Otoguro K, Omura S, Yamada H. Antimalarial activity of biflavonoids from Ochna integerrima. Planta Med 2006; 72: 611-614

[68] Muiva-Mutisya LM, Atilaw Y, Heydenreich M, Koch A, Akala HM, Cheruiyot AC, Brown ML, Irungu B, Okalebo FA, Derese S, Mutai C, Yenesew A. Antiplasmodial prenylated flavanonols from Tephrosia subtriflora. Nat Prod Res 2018; 32: 1407-1414

[69] Hellmann JK, Münter S, Wink M, Frischknecht F. Synergistic and additive effects of epigallocatechin gallate and digitonin on Plasmodium sporozoite survival and motility. PLoS One 2010; 5: e8682

[70] Ramanandraibe V, Grellier P, Martin MT, Deville A, Joyeau R, Ramanitrahasimbola D, Mouray E, Rasoanaivo P, Mambu L. Antiplasmodial phenolic compounds from Piptadenia pervillei. Planta Med 2008; 74: 417-421

[71] Budiman I, Tjokropranoto R, Widowati W, Rahardja F, Maesaroh M, Fauziah N. Antioxidant and anti-malarial properties of catechins. Br J Med Med Res 2015; 5: 895-902

[72] Sharma SK, Parasuraman P, Kumar G, Surolia N, Surolia A. Green tea catechins potentiate triclosan binding to enoyl-ACP reductase from Plasmodium falciparum (PfENR). J Med Chem 2007; 50: 765-775

[73] Thipubon P, Tipsuwan W, Uthaipibull C, Santitherakul S, Srichairatanakool S. Anti-malarial effect of 1-(N-acetyl-6-aminohexyl)-3-hydroxy-2methylpyridin-4-one and green tea extract on erythrocyte-stage Plasmodium berghei in mice. Asian Pac J Trop Biomed 2015; 5: 932-936

[74] Symonowicz M, Kolanek M. Biotechnology and food sciences flavonoids and their properties to form chelate complexes. Biotechnol Food Sci 2012; 76: 35-41

[75] Thipubon P, Uthaipibull C, Kamchonwongpaisan S, Tipsuwan W, Srichairatanakool S. Inhibitory effect of novel iron chelator, 1-(N-acetyl-6aminohexyl)-3-hydroxy-2-methylpyridin-4-one (CM1) and green tea extract on growth of Plasmodium falciparum. Malar ] 2015; 14: 1-9

[76] Tekwani B, Walker L. Targeting the hemozoin synthesis pathway for new antimalarial drug discovery: technologies for in vitro b-hematin formation assay. Comb Chem High Throughput Screen 2005; 8: 63-79

[77] Nitie-Kang F, Onguéne PA, Lifongo LL, Ndom JC, Sippl W, Mbaze LM. The potential of anti-malarial compounds derived from African medicinal plants, part II: a pharmacological evaluation of non-alkaloids and non-terpenoids. Malar J 2014; 13: 1-20

[78] Ferrer P, Vega-Rodriguez J, Tripathi AK, Jacobs-Lorena M, Sullivan D]. Antimalarial iron chelator FBS0701 blocks transmission by Plasmodium falciparum gametocyte activation inhibition. Antimicrob Agents Chemother 2015; 59: 1418-1426

[79] Dettrakul S, Surerum S, Rajviroongit S, Kittakoop P. Biomimetic transformation and biological activities of globiferin, a terpenoid benzoquinone from Cordia globifera. J Nat Prod 2009; 72: 861-865
[80] Vega AS, Rojano B, Blair S, Segura C, Figadere B, Seon B, Grellier P, Sáez ]. Antimalarials and antioxidants compounds from Piper tricuspe (Piperaceae). Pharmacologyonline 2008; 1: 1-8

[81] Fujisaki R, Kamei K, Yamamura M, Nishiya H, Inouye S, Takahashi M, Abe S. In vitro and in vivo anti-plasmodial activity of essential oils, including hinokitiol. Southeast Asian J Trop Med Public Health 2012; 43: 270 279

[82] Johnson-Ajinwo OR, Ullah I, Mbye H, Richardson A, Horrocks P, Li WW. The synthesis and evaluation of thymoquinone analogues as anti-ovarian cancer and antimalarial agents. Bioorganic Med Chem Lett 2018; 28: 1219-1222

[83] Khader M, Eckl PM. Thymoquinone: An emerging natural drug with a wide range of medical applications. Iran J Basic Med Sci 2014; 17: 950 957

[84] Weiss CR, Moideen SVK, Croft SL, Houghton PJ. Activity of extracts and isolated naphthoquinones from Kigelia pinnata against Plasmodium falciparum. J Nat Prod 2000; 63: 1306-1309

[85] Kuete V, Omosa LK, Tala VRS, Midiwo JO, Mbaveng AT, Swaleh S, Sivas H. Chytotoxicity of plumbagin, rapanone and 12 other naturally occurring quinones from Kenyan flora toward human carcinoma cells. BMC Pharmacol Toxicol 2016; 17: 1-10

[86] Sumsakul W, Plengsuriyakarn T, Chaijaroenkul W, Viyanant V, Karbwang J. Antimalarial activity of plumbagin in vitro and in animal models. BMC Complement Altern Med 2014; 14: 1-6

[87] Likhitwitayawuid K, Kaewamatawong R, Ruangrungsi N, Krungkrai J. Antimalarial naphthoquinones from Nepenthes thorelii. Planta Med 1998; 64: 237-241

[88] Perez H, Diáz F, Medina JD. Chemical investigation and in vitro antimalarial activity of Tabebuia ochracea ssp. Neochrysantha. Int J Pharmacogn 1997: 35: 227-231

[89] Dagne E, Steglich W. Knipholone: a unique anthraquinone derivative from Kniphofia foliosa. Phytochemimy 1984; 23: 1729-1731

[90] Bringmann G, Menche D, Bezabih M, Abegaz B, Kaminsky R. Antiplasmodial activity of knipholone and related natural phenylanthraquinones. Planta Med 1999; 65: 757-758

[91] Abegaz BM, Bezabih M, Msuta T, Brun R, Menche D, Mühlbacher J, Bringmann G. Gaboroquinones $A$ and $B$ and 4 '-O-demethylknipholone$4^{\prime}$-O- $\beta$-D-glucopyranoside, phenylanthraquinones from the roots of $\mathrm{Bul}$ bine frutescens. J Nat Prod 2002; 65: 1117-1121

[92] François G, Steenackers T, Assi LA, Steglich W, Lamottke K, Holenz J Bringmann $\mathrm{G}$. Vismione $\mathrm{H}$ and structurally related anthranoid compounds of natural and synthetic origin as promising drugs against the human malaria parasite Plasmodium falciparum: structure-activity relationships. Parasitol Res 1999; 85: 582-588

[93] Laphookhieo S, Maneerat W, Koysomboon S. Antimalarial and cytotoxic phenolic compounds from Cratoxylum maingayi and Cratoxylum cochinchinense. Molecules 2009; 14: 1389-1395

[94] Lenta BN, Devkota KP, Ngouela S, Boyom FF, Naz Q, Choudhary MI, Tsamo E, Rosenthal PJ, Sewald N. Anti-plasmodial and cholinesterase inhibiting activities of some constituents of Psorospermum glaberrimum. Chem Pharm Bull (Tokyo) 2008; 56: 222-226

[95] Lenta NN, Silverre N, Fabrice FB, Tantangmo F, Guy RF, Tsamo E, Gut J Philip JR, Connolly JD. Anti-plasmodial activity of some constituents of the root bark of Harungana madagascariensis L. (Hypericaceae). Chem Pharm Bull 2007; 55: 464-467

[96] Noungoue DT, Chaabi M, Ngouela S, Antheaume C, Boyom FF, Gut ] Rosenthal PJ, Lobstein A, Tsamo E. Antimalarial compounds from the stem bark of Vismia laurentii. Z Naturforsch C J Biosci 2009; 64: 210-214

[97] Hou Y, Cao S, Brodie P], Callmander MW, Ratovoson F, Rakotobe EA, Rasamison VE, Ratsimbason M, Alumasa JN, Roepe PD, Kingston DGI. Antiproliferative and antimalarial anthraquinones of Scutia myrtina from the Madagascar forest. Bioorg Med Chem 2009; 17: 2871-2876 
[98] Achenbach H, Waibel R, Nkunya MHH, Weenen H. Antimalarial compounds from Hoslundia opposita. Phytochemistry 1992; 31: 37813784

[99] Liu XW, Sok DE. Identification of alkylation-sensitive target chaperone proteins and their reactivity with natural products containing michael acceptor. Arch Pharm Res 2003; 26: 1047-1054

[100] Figueiredo JN, Räz B, Séquin U. Novel quinone methides from Salacia kraussii with in vitro antimalarial activity. J Nat Prod 1998; 61: 718-723

[101] Sreeramulu S, Gande SL, Göbel M, Schwalbe H. Molecular mechanism of inhibition of the human protein complex hsp90-cdc37, a kinome chaperone-cochaperone, by triterpene celastrol. Angew Chemie Int Ed 2009; 48: 5853-5855

[102] Zhou Q. Natural Diterpene and Triterpene Quinone Methides: Structures, Synthesis, and biological Potentials. In: Rokita SE, ed. Quinone Methides. Hoboken, NJ: John Wiley \& Sons, Inc.; 2009: 269-295

[103] Toteva MM, Richard JP. The generation and reactions of quinone methides. Adv Phys Org Chem; 2011: 39-91

[104] Rokita SE. Reversible Alkylation of DNA. In: Rokita SE, ed. Quinone Methides. Hoboken, NJ: John Wiley \& Sons, Inc.; 2009: 297-327

[105] Gutiérrez RMP. Handbook of Compounds with antiprotozoal Activity isolated from Plants. New York: Nova Science Publishers, Inc.; 2007

[106] Grellier P, Nemeikaitè-Čènienè A, Šarlauskas ], Čènas N. Role of singleelectron oxidation potential and lipophilicity in the antiplasmodial in vitro activity of polyphenols: comparison to mammalian cells. Z Naturforsch C J Biosci 2008; 63: 445-450

[107] Li WW, Heinze J, Haehnel W. Site-specific binding of quinones to proteins through thiol addition and addition-elimination reactions. J Am Chem Soc 2005; 127: 6140-6141

[108] Portela C, Afonso CMM, Pinto MMM, Ramos MJ. Definition of an electronic profile of compounds with inhibitory activity against hematin aggregation in malaria parasite. Bioorganic Med Chem 2004; 12: 3313-3321

[109] Mahabusarakam W, Kuaha K, Wilairat P, Taylor W. Prenylated xanthones as potential antiplasmodial substances. Planta Med 2006; 72: 912-916

[110] Azebaze AGB, Dongmo AB, Meyer M, Ouahouo BMW, Valentin A, Laure Nguemfo E, Nkengfack AE, Vierling W. Antimalarial and vasorelaxant constituents of the leaves of Allanblackia monticola (Guttiferae). Ann Trop Med Parasitol 2007; 101: 23-30

[111] Hay AE, Hélesbeux J], Duval O, Labaïed M, Grellier P, Richomme P. Antimalarial xanthones from Calophyllum caledonicum and Garcinia vieillardii. Life Sci 2004; 75: 3077-3085

[112] Lenta BN, Kamdem LM, Ngouela S, Tantangmo F, Devkota KP, Boyom FF, Rosenthal PJ, Tsamo E. Antiplasmodial constituents from the fruit pericarp of Pentadesma butyracea. Planta Med 2011; 77: 377-379

[113] Upegui Y, Robledo SM, Gil Romero JF, Quiñones W, Archbold R, Torres F, Escobar G, Nariño B, Echeverri F. In vivo antimalarial activity of $\alpha$ mangostin and the new xanthone $\delta$-mangostin. Phyther Res 2015; 29: 1195-1201

[114] Ngouela S, Lenta BN, Noungoue DT, Ngoupayo J, Boyom FF, Tsamo E, Gut J, Rosenthal PJ, Connolly JD. Anti-plasmodial and antioxidant activities of constituents of the seed shells of Symphonia globulifera Linn $\mathrm{f}$. Phytochemistry 2006; 67: 302-306

[115] De Souza NB, Carmo AML, Da Silva AD, França TCC, Krettli AU. Antiplasmodial activity of chloroquine analogs against chloroquine-resistant parasites, docking studies and mechanisms of drug action. Malar ] 2014; 13: 1-12

[116] Hanboonkunupakarn B, White NJ. The threat of antimalarial drug resistance. Trop Dis Travel Med Vaccines 2015; 2 : 1-5

[117] De Andrade-Neto VF, Da Silva T, Lopes LMX, Do Rosário VE, Varotti FDP, Krettli AU. Antiplasmodial activity of aryltetralone lignans from Holostylis reniformis. Antimicrob Agents Chemother 2007; 51: 23462350
[118] Zhang HJ, Tamez PA, Hoang VD, Tan GT, Hung NV, Xuan LT, Huong LM, Cuong NM, Thao DT, Soejarto DD, Fong HHS, Pezzuto JM. Antimalarial compounds from Rhaphidophora decursiva. J Nat Prod 2001; 64: 772-777

[119] Kharazmi A, Chen M, Theander T, Christensen SB. Discovery of oxygentade chalcones as novel antimalarial agents. Ann Trop Med Parasitol 1997; 91: S91-S95

[120] Mishra LC, Bhattacharya A, Bhasin VK. Phytochemical licochalcone A enhances antimalarial activity of artemisinin in vitro. Acta Trop 2009; 109: 194-198

[121] Yadav N, Dixit SK, Bhattacharya A, Mishra LC, Sharma M, Awasthi SK, Bhasin VK. Antimalarial activity of newly synthesized chalcone derivatives in vitro. Chem Biol Drug Des 2012; 80: 340-347

[122] Chen M, Theander TG, Christensen SB, Hviid L, Zhai L, Kharazmi A. Licochalcone A, a new antimalarial agent, inhibits in vitro growth of the human malaria parasite Plasmodium falciparum and protects mice from P. yoelii infection. Antimicrob Agents Chemother 1994; 38 : 1470-1475

[123] Nowakowska Z. A review of anti-infective and anti-inflammatory chalcones. Eur J Med Chem 2007; 42: 125-137

[124] Lenta BN, Ateba JT, Chouna JR, Aminake MN, Nardella F, Pradel G, Neumann B, Stammler HG, Vonthron-Sénécheau C, Ngouela S, Sewald N. Two 2, 6-Dioxabicyclo[3.3.1]nonan-3-ones from Phragmanthera capitata (Spreng.) Balle (Loranthaceae). Helv Chim Acta 2015; 98 : 945-952

[125] Muhammad I, Li XC, Dunbar DC, ElSohly MA, Khan IA. Antimalarial (+)trans-hexahydrodibenzopyran derivatives from Machaerium multiflorum. J Nat Prod 2001; 64: 1322-1325

[126] World Health Organization. WHO Traditional Medicine Strategy: 2014-2023. Geneva: World Health Organization; 2013

[127] Mukherjee PK. Plant Metabolomics and Quality Evaluation of herbal Drugs. In: Mukherjee PK. Quality Control and Evaluation of herbal Drugs. Amsterdam: Elsevier Inc.; 2019: 629-653

[128] Weniger B, Vonthron-Sénécheau C, Arango G], Kaiser M, Brun R, Anton R. A bioactive biflavonoid from Campnosperma panamense. Fitoterapia 2004; 75: 764-767

[129] Milatovic D, Zaja-Milatovic S, Gupta RC. Oxidative Stress and Excitotoxicity: Antioxidants from Nutraceuticals. In: Gupta RC, ed. Nutraceuticals: Efficacy, Safety and Toxicity. Amsterdam: Elsevier Inc.; 2016: 401-413

[130] Isah MB, Ibrahim MA. The role of antioxidants treatment on the pathogenesis of malarial infections: a review. Parasitol Res 2014; 113: 801809

[131] Ginsburg H, Stein WD. New permeability pathways induced by the malarial parasite in the membrane of its host erythrocyte: potential routes for targeting of drugs into infected cells. Biosci Rep 1987; 7: 455-463

[132] Goodyer ID, Pouvelle B, Schneider TG, Trelka DP, Taraschi TF. Characterization of macromolecular transport pathways in malaria-infected erythrocytes. Mol Biochem Parasitol 1997; 87: 13-28

[133] Ignatushchenko MV, Winter RW, Bächinger HP, Hinrichs DJ, Riscoe MK. Xanthones as antimalarial agents; studies of a possible mode of action. FEBS Lett 1997; 409: 67-73

[134] Burrows JN, Van Huijsduijnen RH, Möhrle JJ, Oeuvray C, Wells TN. Designing the next generation of medicines for malaria control and eradication. Malar J 2013; 12: 1-20

[135] Aditya NP, Vathsala PG, Vieira V, Murthy RSR, Souto EB. Advances in nanomedicines for malaria treatment. Adv Colloid Interface Sci 2013; 201-202: 1-17

[136] Aldrich C, Bertozzi C, Georg Gl, Kiessling L, Lindsley C, Liotta D, Merz KM, Schepartz A, Wang S. The ecstasy and agony of assay interference compounds. J Med Chem 2017; 60: 2165-2168

[137] Baell J, Walters MA. Chemical con artists foil drug discovery. Nature 2014; 513: 481-483 
[138] Baell JB. Feeling nature's PAINS: natural products, natural product drugs, and pan assay interference compounds (PAINS). J Nat Prod 2016; 79: 616-628

[139] Baell JB, Holloway GA. New substructure filters for removal of pan assay interference compounds (PAINS) from screening libraries and for their exclusion in bioassays. J Med Chem 2010; 53: 2719-2740

[140] Ingólfsson HI, Thakur P, Herold KF, Hobart EA, Ramsey NB, Periole X, de Jong DH, Zwama M, Yilmaz D, Hall K, Maretzky T, Hemmings HC, Blobel C, Marrink SJ, Koçer A, Sack JT, Andersen OS. Phytochemicals perturb membranes and promiscuously alter protein function. ACS Chem Biol 2014; 9: 1788-1798

[141] Baell JB, Nissink JWM. Seven year itch: pan-Assay interference compounds (PAINS) in 2017 - utility and limitations. ACS Chem Biol 2018; 13: $36-44$

[142] Marijon A, Bonnot G, Fourier A, Bringer C, Lavoignat A, Gagnieu MC, Bienvenu AL, Picot S. Efficacy of intranasal administration of artesunate in experimental cerebral malaria. Malar J 2014; 13: 501

[143] Mostafa AE, El-Hela AA, Mohammad AEI, Cutler S], Ross SA. New triterpenoidal saponins from Koelreuteria paniculata. Phytochem Lett 2016; 17: $213-218$

[144] Zofou D, Kengne ABO, Tene M, Ngemenya MN, Tane P, Titanji VPK. In vitro antiplasmodial activity and cytotoxicity of crude extracts and compounds from the stem bark of Kigelia africana (Lam.) Benth (Bignoniaceae). Parasitol Res 2011; 108: 1383-1390

[145] Muganga R, Angenot L, Tits M, Frederich M. In vitro and in vivo antiplasmodial activity of three Rwandan medicinal plants and identification of their active compounds. Planta Med 2014; 80: 482-489

[146] Njomnang Soh P, Witkowski B, Gales A, Huyghe E, Berry A, Pipy B, Benoit-Vical F. Implication of glutathione in the In vitro antiplasmodial mechanism of action of ellagic acid. PLoS One 2012; 7: e45906

[147] Nunome S, Ishiyama A, Kobayashi M, Otoguro K, Kiyohara H, Yamada $\mathrm{H}$, Omura S. In vitro antimalarial activity of biflavonoids from Wikstroemia indica. Planta Med 2004; 70: 76-78

[148] Pavanandt K, Webster HK, Yongvanitchit K, Kun-anake A, Dechatiwongse T, Nutakul W, Bansiddhi J. Schizontocidal activity of Celastrus paniculatus Willd. against Plasmodium falciparum in vitro. Phyther Res 1989; 3: 136-139

[149] Azebaze AGB, Meyer M, Valentin A, Nguemfo EL, Fomum ZT, Nkengfack AE. Prenylated xanthone derivatives with antiplasmodial activity from Allanblackia monticola Staner L.C. Chem Pharm Bull (Tokyo) 2006; 37: 111-113

[150] Okada K, Tamura Y, Yamamoto M, Inoue Y, Takagaki R, Takahashi K, Demizu S, Kajiyama K, Hiraga Y, Kinoshita T. Identification of antimicrobial and antioxidant constituents from licorice of Russian and Xinjiang origin. Chem Pharm Bull (Tokyo) 1989; 37: 2528-2530 